\title{
Biomass Derivative Valorization Using Nano Core-Shell Magnetic Materials Based on Keggin-Heteropolyacids: Levulinic Acid Esterification Kinetic Study with N-Butanol
}

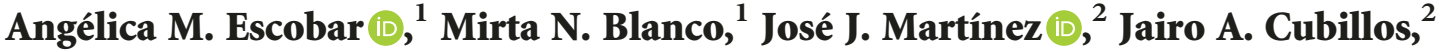 \\ Gustavo P. Romanelli, ${ }^{1}$ and Luis R. Pizzio ${ }^{1}{ }^{1}$ \\ ${ }^{1}$ Centro de Investigación y Desarrollo en Ciencias Aplicadas "Dr. Jorge J. Ronco" (CINDECA), Departamento de Química, Facultad de \\ Ciencias Exactas, UNLP-CIC-CCT La Plata, CONICET, 47 No. 257, B1900AJK La Plata, Argentina \\ ${ }^{2}$ Grupo Catálisis UPTC, Escuela de Ciencias Químicas, Facultad de Ciencias, Universidad Pedagógica y Tecnológica de \\ Colombia UPTC, Avenida Central del Norte, Vía Paipa, Tunja, Boyacá, Colombia
}

Correspondence should be addressed to Luis R. Pizzio; lrpizzio@quimica.unlp.edu.ar

Received 30 October 2018; Revised 3 April 2019; Accepted 15 April 2019; Published 12 May 2019

Academic Editor: Paulo Cesar Morais

Copyright (c) 2019 Angélica M. Escobar et al. This is an open access article distributed under the Creative Commons Attribution License, which permits unrestricted use, distribution, and reproduction in any medium, provided the original work is properly cited.

\begin{abstract}
Magnetic materials based on Keggin heteropolyacids immobilized on mesoporous silica-coated magnetite particles with a coreshell structure were synthesized. The activity of the catalyst was studied in the esterification reaction of levulinic acid with nbutanol, and its kinetics was studied by the systematic variation of several reaction parameters, such as stirring speed, catalyst loading, molar ratio of reactants, and temperature. It was also seen that the reaction was free from any external mass transfer as well as intraparticle diffusion limitations and was intrinsically kinetically controlled. A second-order kinetic equation was found to be consistent with the experimental data. Also, an experimental activation energy of $17 \mathrm{kcal} / \mathrm{mol}$ was found. A solvent-free condition for this reaction has also added the green chemistry perception to the reaction. In addition, the resulting catalyst can be used repeatedly without significant decrease in activity.
\end{abstract}

\section{Introduction}

In recent years, great interest has been aroused in biomass waste and the carbohydrates derived from it, as they are abundant and relatively inexpensive and are a promising renewable source of carbon. The biomass is a useful chemical platform for synthesizing a broad range of products such as fuels, additives, and fine chemicals in general, thus representing an alternative to petroleum-derived products $[1,2]$. Biomass wastes include any organic material other than the raw material for which they were planted, e.g., waste from leaves and bagasse from the sugar cane during sugar production or paper or fruit peels and seeds in the food industry [3]. Thus, biorefineries are born, which are becoming increasingly important in the development of new sustainable technologies and are defined as an industry that, through different technological processes (mechanical, physical, and biochemical), separates renewable raw materials into their main components such as triglycerides, carbohydrates, and proteins to produce energy and valueadded chemicals analogously to how oil refineries process crude oil to produce specialty chemicals $[4,5]$. In 2004, researchers from the NREL (National Renewable Energy Laboratory) and PNNL (Pacific Northwest National Laboratory) conducted an extensive study to identify the most valuable building blocks based on sugars from lignocellulosic biomass [6]. Out of 300 candidates initially selected, the number was reduced to twelve, one of these top twelve promising building blocks being 4-oxopentanoic acid, known commercially as levulinic acid (LEA). In 2010, it was reconfirmed in the top 10 list, after an updated assessment of possible building blocks in which the advances of technology that led to the inclusion of a compound in the first listing were evaluated [7] (Scheme 1 shows some useful 


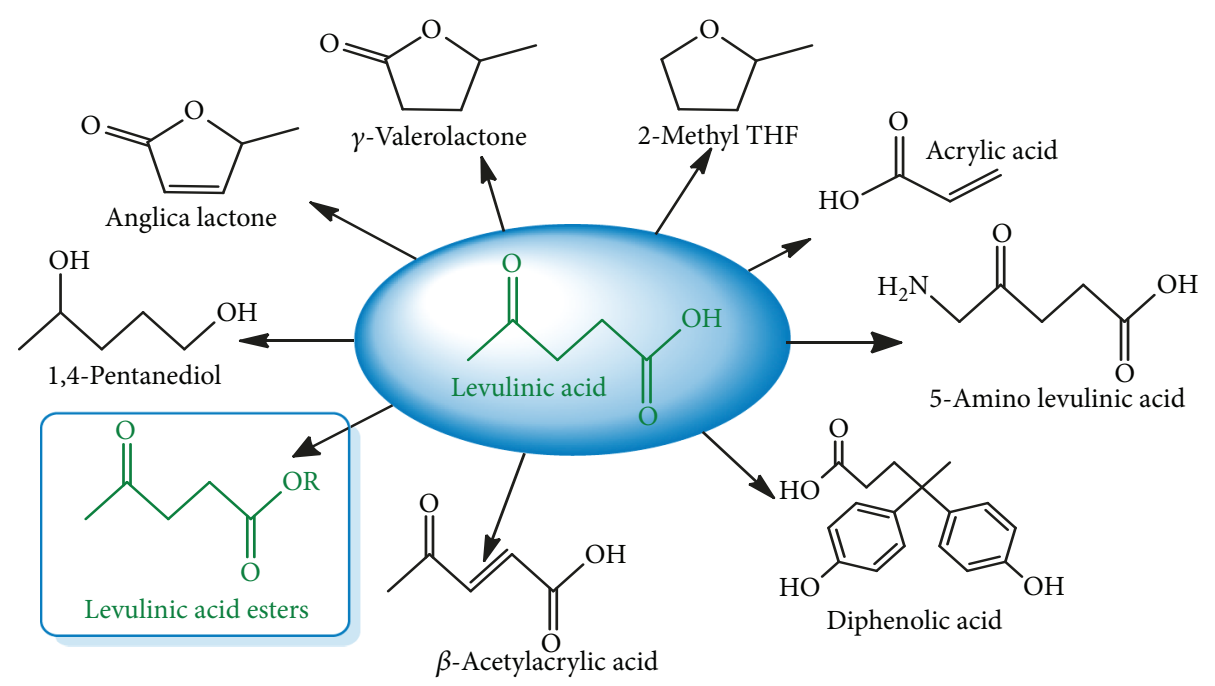

Scheme 1: Chemical compounds of great unit value that could be obtained from LEA.

compounds derived from LEA). Hence, various investigations on how to synthesize LEA and different by-products from biomass derivatives are being carried out. Among them, the alkyl levulinates (ALE), especially n-butyl levulinate (BLE), are of great importance, because they currently have extensive applications, either as a fragrance [8] or as an additive in gasoline and biodiesel, among others [9].

Most of the current industrial processes for the production of LEA and ALE use sulfuric and phosphoric acids as catalysts in each of the steps [10], which involves disadvantages harmful to health and the environment due to its toxicity. For these reasons, this study focuses on providing a heterogeneous catalyst that facilitates the process and the performance of the industrial scale reaction. In this sense, the Fischer esterification of LEA with n-butanol (BOH) to synthesize BLE was chosen as the study reaction using a magnetic solid with tungstophosphoric acid (TPA) as active phase as catalyst, denominated $\mathrm{Fe}_{3} \mathrm{O}_{4} @ \mathrm{SiO}_{2} @ \mathrm{SiO}_{2} / \mathrm{T}$ $\mathrm{PA}_{400 \mathrm{~N} 2}$. To date, there are few reports on the kinetics of this reaction. In general, Bart et al. [11] gave kinetic information about the esterification of LEA with $\mathrm{BOH}$ with sulfuric acid as a homogeneous catalyst. Subsequently, Nandiwale and Bokade [12] studied the kinetics of the same reaction using modified H-ZSM-5 catalysts. Now, we intend to extend these kinetic studies and report data on diffusion effects, kinetic equation, and activation energy.

On the other hand, in the study of magnetic materials as catalysts, the core-shell structure has attracted increasing attention due to two main reasons: (i) the magnetic center allows controlling its dispersion in a reversible way by applying a magnetic field. Namely, without the presence of an external magnetic field, the nanoparticles are dispersed in the solution, redistributing their surface area facilitating the contact with the substrate molecules. After completing the reactions, the nanoparticles can be easily isolated from the system by approaching a magnet [13]. (ii) The coating serves as an anchor point for different materials and functional groups and thus, for example, immobilizes homogeneous catalysts [14].
The magnetic nanoparticles (MNPs) were synthesized by the coprecipitation method, by means of iron salts $\left(\mathrm{Fe}^{2+} /\right.$ $\mathrm{Fe}^{3+}$ ) in ammonia solution under a nitrogen atmosphere. This method is widely used because it is simple and economical and has a high reaction yield and a narrow size distribution [15]. One of the disadvantages of the magnetite particles is that they are susceptible to oxidation by environmental factors or by acid reaction conditions. This makes it necessary to encapsulate them with an organic/inorganic polymer shell or stabilize them with a surfactant, further conferring an active surface to anchor the active phase of the catalyst $[16,17]$. The most commonly used coating material is silicon oxide because it is chemically inert, nontoxic, and relatively easy to synthesize by the sol-gel method [18]. The TPA was included during the coating of the magnetic particles with the silicon oxide. There are a few studies on this type of catalyst, in which the heteropoly acid is generally added by impregnation and has never been evaluated in this esterification reaction [19-22].

The characterization techniques used were IR/FT, XRD, BET, SEM, VSM, and potentiometric titration. The best reaction conditions, in terms of reactant molar ratio, catalyst loading, temperature, and reaction time, were established, as was the reuse of the catalyst. A possible catalytic mechanism for the esterification reaction is also proposed.

\section{Experimental}

2.1. General. All chemical reagents and solvents were of commercial analytical grade and were used without further purification. The progress and conversion of the reactions were quantified by GC/FID in a Shimadzu chromatograph model 2014, using a FID detector and a capillary column (SPB-1, length $30 \mathrm{~m}$, I.D. $32 \mathrm{~mm}$, and film thickness $1.00 \mu \mathrm{m}$ ). The carrier gas was high-purity nitrogen $(\geqq 99.999 \%)$, and the optimum conditions were as follows: splitless injection mode was used $(1 \mu \mathrm{L})$, the injector temperature was set at $320^{\circ} \mathrm{C}$, the initial column temperature was $150^{\circ} \mathrm{C}$ (held for $2 \mathrm{~min}$ ), then ramped at $20^{\circ} \mathrm{C} / \mathrm{min}$ to $200^{\circ} \mathrm{C}$, and the FID temperature 
was $300^{\circ} \mathrm{C}$. Conversions were determined by the relative peak areas of the substrates and products using a normalization method. The retention times of LEA and BLE were 3.42 and $6.15 \mathrm{~min}$, respectively. For more details on the quantification method, see Supplementary Material (available here).

\subsection{Catalyst Preparation}

2.2.1. Synthesis of $\mathrm{Fe}_{3} \mathrm{O}_{4}$ Nanoparticles. $\mathrm{Fe}_{3} \mathrm{O}_{4} \mathrm{MNPs}$ were synthesized through the chemical coprecipitation method of iron salts in an ammonia solution. The salts $\mathrm{FeCl}_{2} \cdot 4 \mathrm{H}_{2} \mathrm{O}$ (1.0) and $\mathrm{FeCl}_{3} \cdot 6 \mathrm{H}_{2} \mathrm{O}(2.7 \mathrm{~g})$ (2:1 molar ratio) were dissolved in water $(25 \mathrm{~mL})$, mixed under vigorous stirring $(1000 \mathrm{rpm})$ with nitrogen bubbling, and heated to $353 \mathrm{~K}$. When they reached the indicated temperature, $12 \mathrm{~mL}$ of concentrated $\mathrm{NH}_{4} \mathrm{OH}$ solution $(25 \% \mathrm{w} / \mathrm{w})$ was added dropwise, controlling the $\mathrm{pH}$ between 11 and 13. Immediately, the solution turned black and was stirred for another $1 \mathrm{~h}$. Then, the $\mathrm{Fe}_{3} \mathrm{O}_{4}$ nanoparticles were precipitated using a magnet. Finally, MNPs were washed repeatedly with water and ethanol to eliminate excess ammonia. Nitrogen was used in the whole process to prevent particle oxidation.

2.2.2. Synthesis of $\mathrm{Fe}_{3} \mathrm{O}_{4} @ \mathrm{SiO}_{2}$. Silica coatings on the $\mathrm{Fe}_{3} \mathrm{O}_{4}$ MNPs were synthesized by the Stölber method with some modifications and basic hydrolysis, utilizing tetraethyl orthosilicate (TEOS) as $\mathrm{SiO}_{2}$ source. One $\mathrm{g}$ of $\mathrm{Fe}_{3} \mathrm{O}_{4}$ MNPs was sonicated for $30 \mathrm{~min}$ in $70 \mathrm{~mL}$ of ethanol and $24 \mathrm{~mL}$ of ammonia solution $(25 \% \mathrm{w} / \mathrm{w})$, at the molar ratio of $1: 6$ with respect to TEOS, heating to $318 \mathrm{~K}$ and with constant stirring. When the temperature was reached, TEOS was added dropwise to the mixture and reacted for $4 \mathrm{~h}$. Then, the ethanol was evaporated at room temperature to dryness while stirring. The particles were separated using a magnet and washed four times with water and ethanol until neutral $\mathrm{pH}$. The MNPs showed no detectable dissolution in a hydrochloric/nitric acid mixture for $24 \mathrm{~h}$.

2.2.3. Synthesis of $\mathrm{TPA} / \mathrm{SiO}_{2}$ Composite Coatings over $\mathrm{Fe}_{2} \mathrm{O}_{4} @ \mathrm{SiO}_{2}$. A second coating was made with $\mathrm{SiO}_{2}$, in which the TPA was simultaneously added, so that it was immobilized in this layer. In this case, the coating was realized by acid hydrolysis of TEOS catalyzed by the same TPA. In a typical experiment, $1 \mathrm{~g}$ of the $\mathrm{Fe}_{3} \mathrm{O}_{4} @ \mathrm{SiO}_{2}$ MNPs was redispersed in $70 \mathrm{~mL}$ of ethanol together with $1 \mathrm{~g}$ of TPA. The obtained mixture was heated to $318 \mathrm{~K}$; when this temperature was reached, $4 \mathrm{~mL}$ of TEOS was slowly added and the heating was stopped. The sample was left under stirring at room temperature until dry. The product was washed with water and ethanol until neutral pH. Finally, the obtained solid was calcined at $673 \mathrm{~K}$ under nitrogen atmosphere for $2 \mathrm{~h}$. The catalyst was called $\mathrm{Fe}_{3} \mathrm{O}_{4} @ \mathrm{SiO}_{2} @ \mathrm{SiO}_{2} / \mathrm{TPA}_{400 \mathrm{~N} 2}$. The amount of TPA was fixed in order to obtain a concentration of $40 \%$ TPA $(w / w)$ in the catalyst.

The TPA content in the catalyst was estimated as the difference between the $\mathrm{W}$ amount contained in the heteropoly acid solution originally used for the impregnation and the amount of $\mathrm{W}$ in the water solutions obtained after the solid washing. The $\mathrm{W}$ content was determined by atomic absorption spectrometry using a Varian AA Model
240 spectrophotometer. The calibration curve method was used with standards prepared in the laboratory. The analyses were carried out at a wavelength of $254.9 \mathrm{~nm}$, band width $0.3 \mathrm{~nm}$, lamp current $15 \mathrm{~mA}$, phototube amplification $800 \mathrm{~V}$, burner height $4 \mathrm{~mm}$, and acetylene-nitrous oxide flame $11: 14$.

2.3. Catalyst Characterization. SEM images were obtained on Philips SEM 505 equipment, using a voltage of $25 \mathrm{eV}$ and increasing from $2500 x$ to $10000 x$. The samples were premetallized with gold. The diameter of the material particles was calculated by direct observation of SEM images using an EDAX Apex 2 analyzer system, Apollo X Model, which has software for obtaining and analyzing digital images.

$\mathrm{XRD}$ diagrams were obtained in order to determine the presence of crystalline phases associated with $\mathrm{Fe}_{3} \mathrm{O}_{4}$ and TPA. They were recorded in PANalytical X'Pert Pro equipment, using $\mathrm{Cu} \mathrm{k} \alpha$ radiation and $\mathrm{Ni}$ filter. The scanning angle was performed in the range $10-90^{\circ}$ of $2 \theta$ using a scan rate of $1 \mathrm{~s}$ and a step size of $0.04^{\circ} \mathrm{s}^{-1}$.

Textural characteristics of materials were obtained from $\mathrm{N}_{2}$ adsorption-desorption isotherms at liquid-nitrogen temperature, using Micromeritics ASAP 2020 equipment. Previously, the solids were degassed at $373 \mathrm{~K}$ for $2 \mathrm{~h}$.

Magnetization measurements were obtained on a vibrating magnetometer VersaLab. For this purpose, $0.01 \mathrm{~g}$ of sample was weighed and a scan of -10000 to +10000 Oe was performed at $300 \mathrm{~K}$.

The chemical groups present during the synthesis of the materials were analyzed on a Nicolet iS50 FTIR spectrophotometer coupled with attenuated total reflectance (ATR). For the analysis, $0.1 \mathrm{~g}$ of each solid was weighed and placed in the ZnSe cell at room temperature, with a scan of 32 scans and a resolution of $6 \mathrm{~cm}^{-1}$. The collected spectra were manipulated with the program OMNIC $5.1^{\circledR}$.

The acid strength was determined by potentiometric titration with $n$-butylamine (for more information about the method, see Supplementary Materials).

2.4. Catalytic Studies. The esterification reaction of LEA with $\mathrm{BOH}$ was selected as a model reaction to evaluate the catalytic activity of $\mathrm{Fe}_{3} \mathrm{O}_{4} @ \mathrm{SiO}_{2} @ \mathrm{SiO}_{2} / \mathrm{TPA}_{400 \mathrm{~N} 2}$ material. For all the optimization tests, the same procedure was followed and the same equipment was used. A reaction tube with a water reflux condenser was used as a reactor. When the chosen temperature was reached, the predetermined amounts of reagents in the tube were added and agitated at $500 \mathrm{rpm}$. An experimental design with three variables was proposed; these include the reaction temperature $(323,333,343$, and $353 \mathrm{~K})$, acid:alcohol molar ratio $(1: 2$, $1: 4,1: 6$, and $1: 8 \mathrm{mmol} / \mathrm{mmol})$, and catalyst amounts $(25$, 50,100 , and $150 \mathrm{mg}$ ). Samples were taken at regular intervals by momentarily reducing the stirring rate and bringing a magnet closer to precipitate the catalyst. In all reactions, the amount of LEA ( $1 \mathrm{mmol}$ ) remained constant, $\mathrm{BOH}$ was in excess with respect to LEA, and the reaction conversion was calculated based on the limiting reagent, LEA. Each parameter was analyzed in triplicate with standard deviations less than $\pm 2 \%$. 


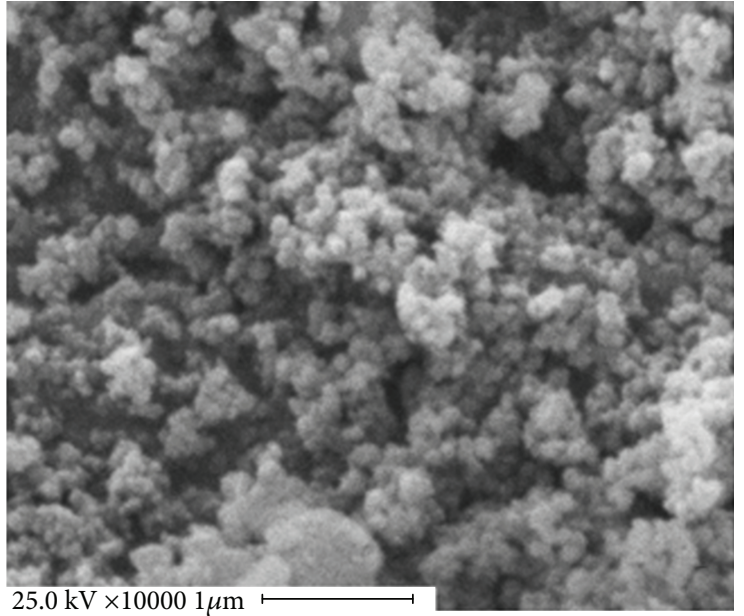

(a)

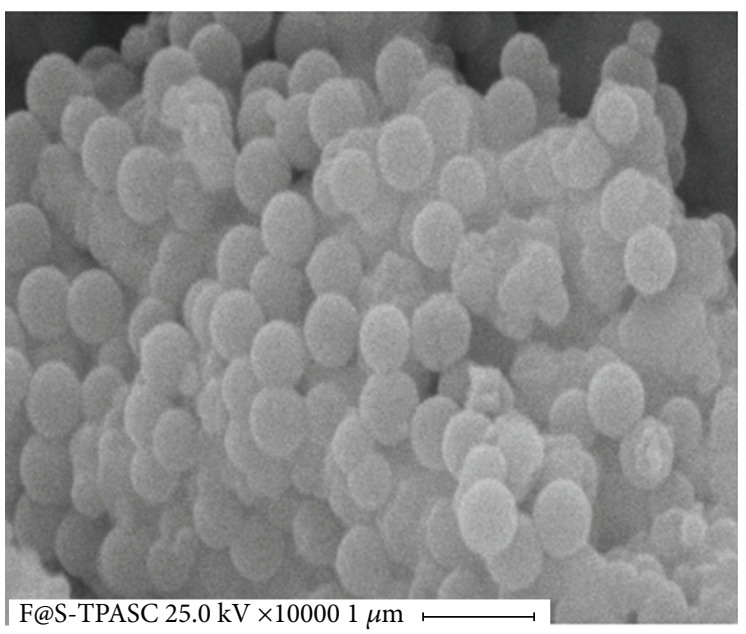

(c)

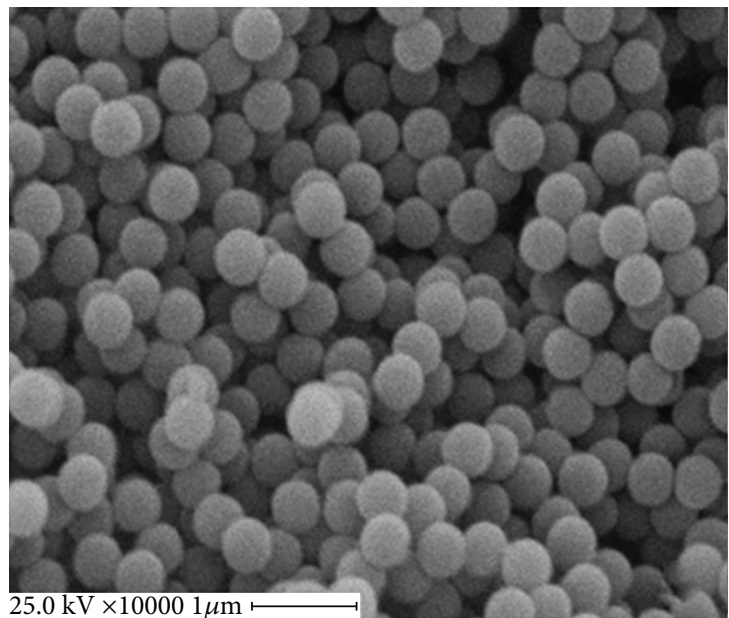

(b)

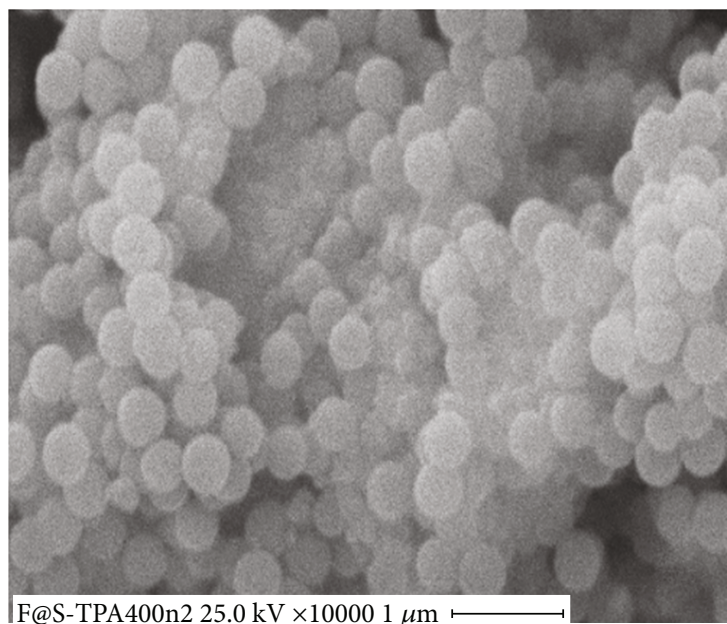

(d)

Figure 1: SEM images of (a) $\mathrm{Fe}_{3} \mathrm{O}_{4}$, (b) $\mathrm{Fe}_{3} \mathrm{O}_{4} @ S_{2}$, (c) $\mathrm{Fe}_{3} \mathrm{O}_{4} @ S_{2} \mathrm{O}_{2} @ \mathrm{SiO}_{2} / \mathrm{TPA}$ without calcination, and (d) $\mathrm{Fe}_{3} \mathrm{O}_{4} @ S_{2} \mathrm{O}_{2} @ S i \mathrm{O}_{2} / \mathrm{TPA}$ calcined at $673 \mathrm{~K}$ under nitrogen atmosphere.

2.5. Catalyst Reuse. To evaluate the reuse of the catalyst, four consecutive experiments were carried out under the same reaction conditions. After each reaction cycle, the catalyst was separated from the reaction system with the aid of a magnet, washed with toluene $(3 \times 2 \mathrm{~mL})$, dried under vacuum, and reused by adjusting the amounts of reactants to the amount of catalyst recovered.

\section{Results and Discussions}

3.1. Catalyst Characterization. The morphological characteristics of each catalytic material obtained in the different stages of catalyst synthesis were analyzed by SEM. Figure 1(a) shows the SEM image of the MNPs prepared through the chemical mixture of ferric and ferrous salts, precipitating as $\mathrm{Fe}_{3} \mathrm{O}_{4}$ by the addition of ammonia, which have a uniform shape and a size around $10 \mathrm{~nm}$. The chemical equation of $\mathrm{Fe}_{3} \mathrm{O}_{4}$ synthesis is shown below:

$$
\mathrm{Fe}^{2+}+2 \mathrm{Fe}^{3+}+8 \mathrm{OH}^{-} \rightarrow \mathrm{Fe}_{3} \mathrm{O}_{4}+4 \mathrm{H}_{2} \mathrm{O}
$$

TABLE 1: Textural properties of the different solids studied.

\begin{tabular}{lccc}
\hline Entry & Solid & $S_{\mathrm{BET}}\left(\mathrm{m}^{2} \mathrm{~g}^{-1}\right)$ & $D_{\mathrm{P}}{ }^{\mathrm{a}}(\mathrm{nm})$ \\
\hline 1 & $\mathrm{Fe}_{3} \mathrm{O}_{4}$ & 6 & - \\
2 & $\mathrm{Fe}_{3} \mathrm{O}_{4} @ \mathrm{SiO}_{2}$ & 20 & 8 \\
3 & $\mathrm{Fe}_{3} \mathrm{O}_{4} @ \mathrm{SiO}_{2} @ \mathrm{SiO}_{2} / \mathrm{TPA}_{\mathrm{SC}}$ & 65 & 7 \\
4 & $\mathrm{Fe}_{3} \mathrm{O}_{4} @ \mathrm{SiO}_{2} @ \mathrm{SiO}_{2} / \mathrm{TPA}_{400 \mathrm{~N} 2}$ & 45 & 9 \\
\hline
\end{tabular}

${ }^{a}$ Average pore diameter estimated from $S_{\mathrm{BET}}$.

Then, the MNPs were sonicated in an alkaline ethanolammonia solution and the magnetic nucleus was coated with silica shells by hydrolysis of TEOS (Figure 1(b)), increasing the size of the nanoparticles to an average diameter of $300 \mathrm{~nm}$. Finally, by means of the second coating with TEOS, TPA was immobilized (Figure 1(c)), increasing the average diameter to $620 \mathrm{~nm}$. In all cases, the particles were spherical and of uniform size. However, some aggregates could be observed after the second $\mathrm{SiO}_{2}$ coating and remained after calcination at $673 \mathrm{~K}$ (Figure $1(\mathrm{~d})$ ). 


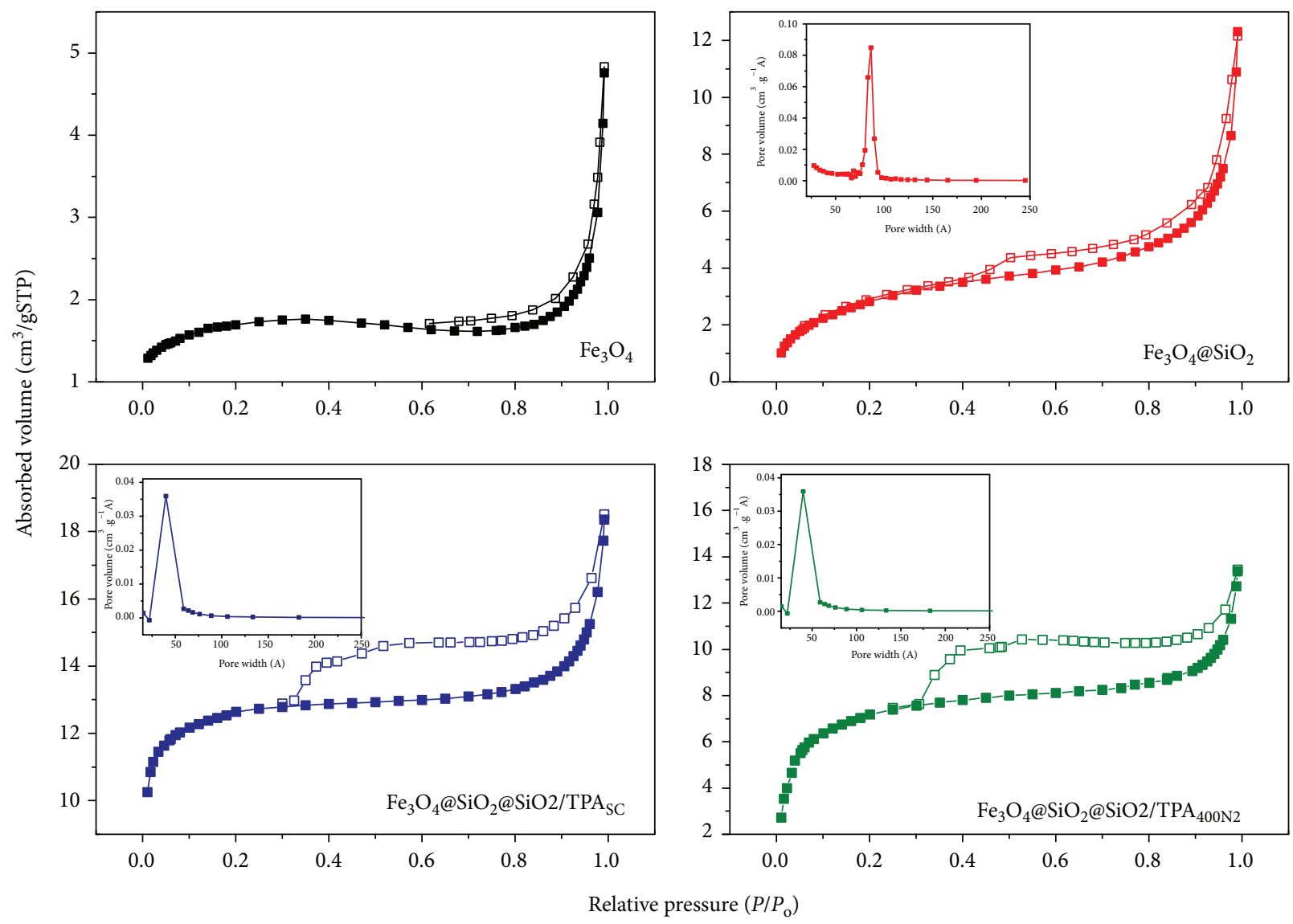

FIgURE 2: Adsorption-desorption isotherms at $77 \mathrm{~K}$ of the different solids.

From the adsorption-desorption nitrogen isotherms at $77 \mathrm{~K}$, the surface areas were estimated applying the Brunauer-Emmett-Teller (BET) equation. Table 1 shows the results obtained from the measurement of the surface area and pore size of the materials. The values determined for the $\mathrm{Fe}_{3} \mathrm{O}_{4}$ magnetic particles show a low $S_{\mathrm{BET}}$ corresponding to $6 \mathrm{~m}^{2} / \mathrm{g}$ (Table 1, entry 1). This area increases to $20 \mathrm{~m}^{2} / \mathrm{g}$ with the first $\mathrm{SiO}_{2}$ coating (Table 1, entry 2) and increases again to $65 \mathrm{~m}^{2} / \mathrm{g}$ when the second coating is made with $\mathrm{SiO}_{2}$ and with the addition of TPA (Table 1 , entry 3 ). The contribution to the total area, due to the presence of micropores, is around $40 \%$ in the sample $\mathrm{Fe}_{3} \mathrm{O}_{4} @ \mathrm{SiO}_{2}$ and decreases to $15 \%$ for $\mathrm{Fe}_{3} \mathrm{O}_{4} @ \mathrm{SiO}_{2} @ \mathrm{SiO}_{2} / \mathrm{TPA}_{\mathrm{SC}}$. When subjecting the catalyst to thermal treatment at $673 \mathrm{~K}$ under a nitrogen atmosphere, $S_{\mathrm{BET}}$ decreases to $45 \mathrm{~m}^{2} / \mathrm{g}$, also decreasing the contribution of micropores (Table 1, entry 4), possibly due to the collapse of the smaller pores, evidenced by an increase in the pore diameter from 7 to $9 \mathrm{~nm}$.

By analyzing the shape and hysteresis loop of the adsorption-desorption isotherms shown in Figure 2, it can be seen that the isotherm for the $\mathrm{Fe}_{3} \mathrm{O}_{4}$ sample is typically type II, characteristic of nonporous, slightly porous, or macroporous materials. Therefore, a pore size for this sample was not determined (Table 1, entry 1). The samples coated with silica and TPA (Table 1, entries 2 to 4) present isotherms type IV, characteristic of mesoporous solids, which is in agreement with the obtained pore diameter. However,

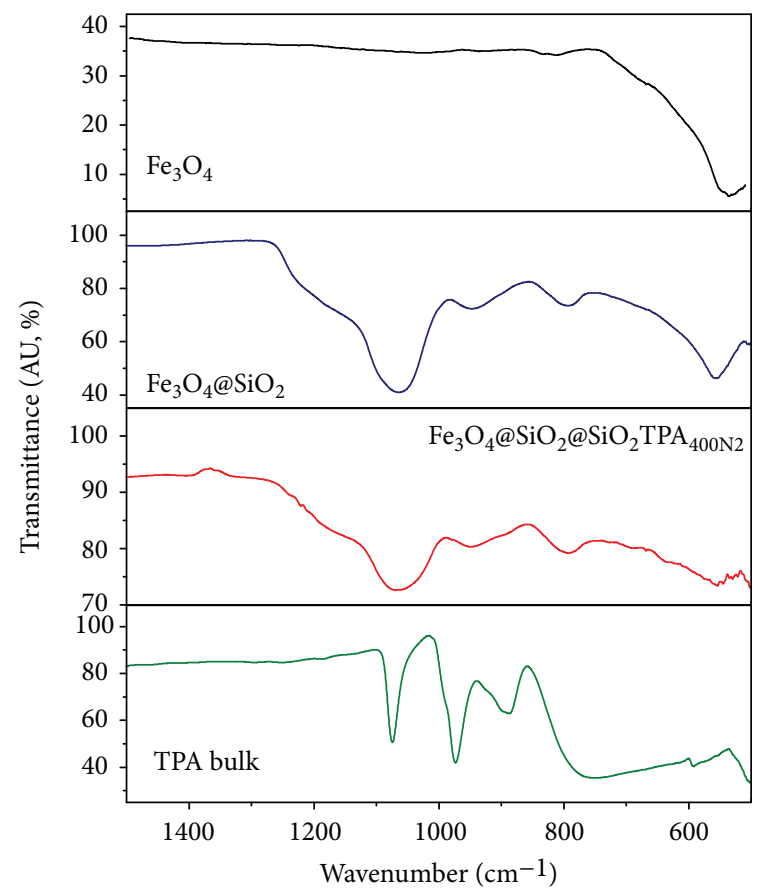

FIGURE 3: FTIR spectra of solids. 


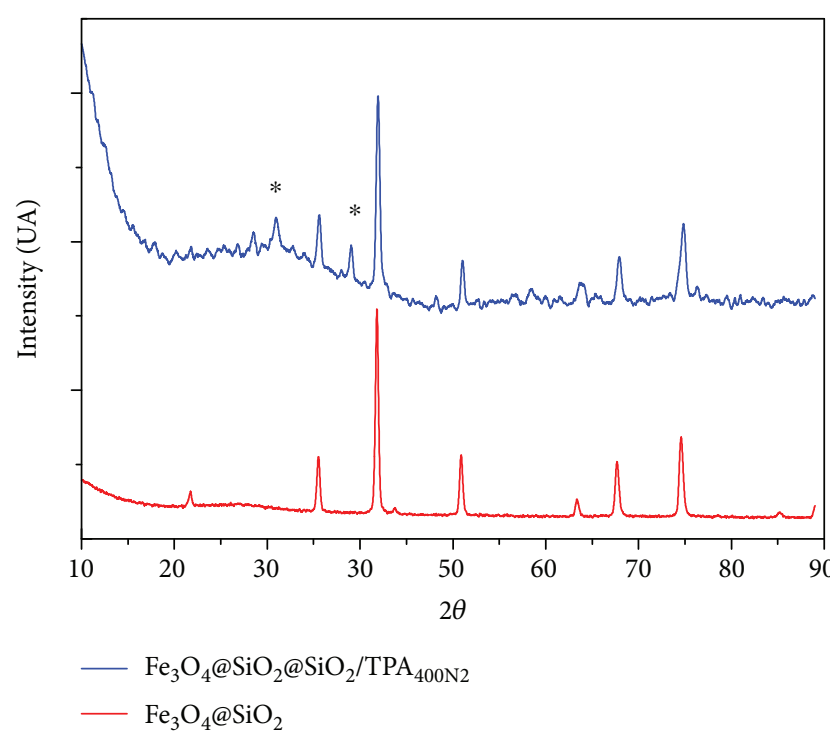

(a)

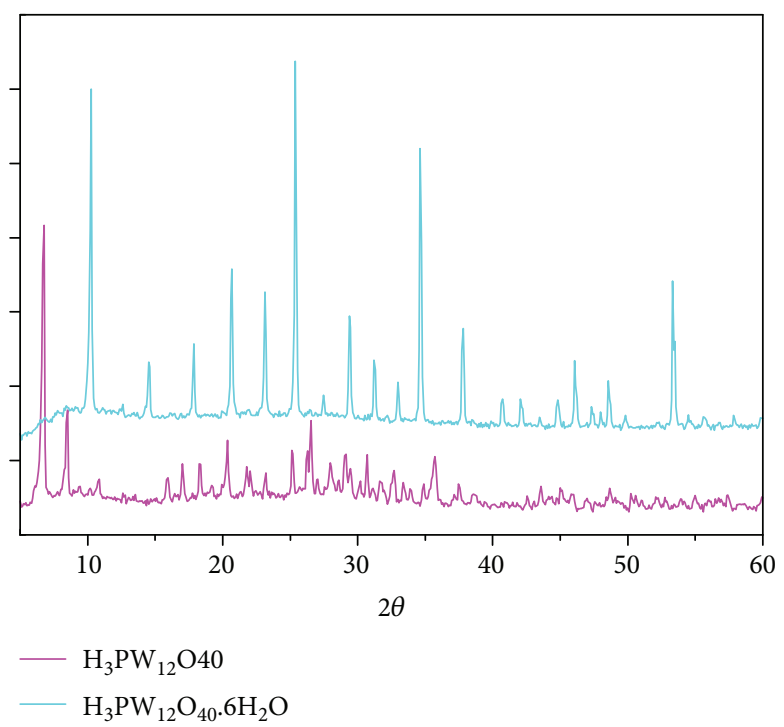

(b)

Figure 4: XRD of the $\mathrm{Fe}_{3} \mathrm{O}_{4} @ \mathrm{SiO}_{2}$ and $\mathrm{Fe}_{3} \mathrm{O}_{4} @ \mathrm{SiO}_{2} @ \mathrm{SiO}_{2} / \mathrm{TPA}_{400 \mathrm{~N} 2}$ samples.

the different cycles of hysteresis suggest that the incorporation of silica and TPA into $\mathrm{Fe}_{3} \mathrm{O}_{4}$ particles modifies the textural properties, which is why it significantly increases its surface area and pore size (Table 1). Thus, the $\mathrm{N}_{2}$-sorption isotherm of $\mathrm{Fe}_{3} \mathrm{O}_{4}$ and $\mathrm{Fe}_{3} \mathrm{O}_{4} @ \mathrm{SiO}_{2}$ magnetic particles exhibits a barely perceptible hysteresis, which increases when the second layer of silica and TPA is added. Hysteresis loops in both uncalcined and calcined catalysts are type $\mathrm{H} 2$.

The FTIR-ATR spectra are shown in Figure 3. In the $\mathrm{Fe}_{3} \mathrm{O}_{4}$ spectrum, the main absorption band is centered at around $540 \mathrm{~cm}^{-1}$, corresponding to stretching vibration of $\mathrm{Fe}-\mathrm{O}$. In the case of sample $\mathrm{Fe}_{3} \mathrm{O}_{4} @ \mathrm{SiO}_{2}$, the characteristic absorption band for the silica network is assigned as follows. The high-intensity broad band at $1080 \mathrm{~cm}^{-1}$ is due to $\mathrm{Si}-\mathrm{O}-\mathrm{Si}$ asymmetric stretching bonds in the $\mathrm{SiO}_{4}$ tetrahedron associated with the movement of oxygen in the $\mathrm{Si}-\mathrm{O}-\mathrm{Si}$ antisymmetric stretch. The signal at $793 \mathrm{~cm}^{-1}$ is assigned to the Si-O-Si symmetric stretch. The absorption band at $960 \mathrm{~cm}^{-1}$ corresponds to stretches of the Si-OH bond. And the absorption band at $564 \mathrm{~cm}^{-1}$ is an indication of the presence of $\mathrm{Si}-\mathrm{O}-\mathrm{Fe}$; this band overlaps the $\mathrm{Fe}-\mathrm{O}$ band of the magnetite [18]. The structure of the Keggin ions of $\left[\mathrm{PW}_{12} \mathrm{O}_{40}\right]^{3-}$ is well known, and their bands have been reported in previous works $[23,24]$ (they are also detailed in Supplementary Material). In the sample $\mathrm{Fe}_{3} \mathrm{O}_{4} @ \mathrm{SiO}_{2} @ \mathrm{SiO}_{2} / \mathrm{TPA}_{400 \mathrm{~N} 2}$, they are overlapped by the wide bands originated from the silica network $[20,22]$.

The XRD of the $\mathrm{Fe}_{3} \mathrm{O}_{4} @ \mathrm{SiO}_{2}$ and $\mathrm{Fe}_{3} \mathrm{O}_{4} @ \mathrm{SiO}_{2} @ \mathrm{SiO}_{2} / \mathrm{T}$ $\mathrm{PA}_{400 \mathrm{~N} 2}$ samples are shown in Figure 4(a). In them, the diffraction peaks located at $2 \theta=18.4^{\circ}, 30.2^{\circ}, 35.6^{\circ}, 43.3^{\circ}$, $53.6^{\circ}$, and $62.6^{\circ}$ are assigned to planes (111), (220), (311), (400), (422), and (440), respectively. They could be assigned to magnetite $\left(\mathrm{Fe}_{3} \mathrm{O}_{4}\right)$ or maghemite $\left(\gamma-\mathrm{Fe}_{2} \mathrm{O}_{3}\right)$ phases, because the diffraction pattern of the cubic form of $\gamma$ - $\mathrm{Fe}_{2} \mathrm{O}_{3}$ is identical to that of $\mathrm{Fe}_{3} \mathrm{O}_{4}$ with some line shift towards higher angles [25]. This makes it difficult to define what iron oxide is synthesized by analyzing the XRD. However, the black color in our samples was maintained, indirectly indicating the preferential formation of magnetite, because magnetite is usually black and pure maghemite is usually brown [26]. In addition, it is evident that the coating with $\mathrm{SiO}_{2}$ and calcination in an inert atmosphere protect the magnetite from oxidizing, since in the sample $\mathrm{Fe}_{3} \mathrm{O}_{4} @ \mathrm{SiO}_{2} @ \mathrm{SiO}_{2} / \mathrm{TPA}_{400 \mathrm{~N} 2}$, the diffraction peaks are exactly the same, although a little less defined and wider because of a greater amount of $\mathrm{SiO}_{2}$, indicating that the silica is in an amorphous form and possibly its small and wide peaks are dominated by the sharp peaks of the magnetite. Even so, a broad peak at $10^{\circ}$ and a shoulder between $25^{\circ}$ and $30^{\circ}$ characteristic of the amorphous silica are observed. Finally, the characteristic diffraction peaks of $\mathrm{H}_{3} \mathrm{PW}_{12} \mathrm{O}_{40} \cdot 23 \mathrm{H}_{2} \mathrm{O}$ and $\mathrm{H}_{3} \mathrm{PW}_{12} \mathrm{O}_{40} \cdot 6 \mathrm{H}_{2} \mathrm{O}$ (shown in Figure 4(b)) are not observed in Figure 4(a) due to a large dispersion of the active phase on the support surface [27, 28]. The small peaks at $30.9^{\circ}$ and $38.8^{\circ}$ (marked with an asterisk in Figure 4(a)) could be assigned to the presence of a small amount of $\mathrm{H}_{3} \mathrm{PW}_{12} \mathrm{O}_{40}$ crystals.

The magnetization curves for the $\mathrm{Fe}_{3} \mathrm{O}_{4}, \mathrm{Fe}_{3} \mathrm{O}_{4} @ \mathrm{SiO}_{2}$, and $\mathrm{Fe}_{3} \mathrm{O}_{4} @ \mathrm{SiO}_{2} @ \mathrm{SiO}_{2} / \mathrm{TPA}_{400 \mathrm{~N} 2}$ materials are shown in Figure 5. The applied magnetic field for these systems confirms the ferromagnetic response of these materials. It can be observed that the $\mathrm{Fe}_{3} \mathrm{O}_{4}$ and $\mathrm{Fe}_{3} \mathrm{O}_{4} @ \mathrm{SiO}_{2}$ curves pass through the origin (Figure 5(a), blue and red lines), giving rise to solids that do not present coercivity or remanence, whish evidences their superparamagnetic behavior $[29,30]$. The magnetization saturation $\left(M_{\mathrm{S}}\right)$ values for these two materials were 87 and $52 \mathrm{emu} / \mathrm{g}$, respectively. The decrease in the $M_{\mathrm{S}}$ value for $\mathrm{Fe}_{3} \mathrm{O}_{4} @ \mathrm{SiO}_{2}$ can be attributed to the deposition of nonmagnetic $\mathrm{SiO}_{2}$ on the $\mathrm{Fe}_{3} \mathrm{O}_{4}$ surface, with the consequent lower amount of magnetite in the same sample weight [28]. However, in the $\mathrm{Fe}_{3} \mathrm{O}_{4} @ \mathrm{SiO}_{2} @ \mathrm{SiO}_{2} / \mathrm{T}$ $\mathrm{PA}_{400 \mathrm{~N} 2}$ solid (Figure 5(a), green line), the $M_{\mathrm{S}}$ value drops 


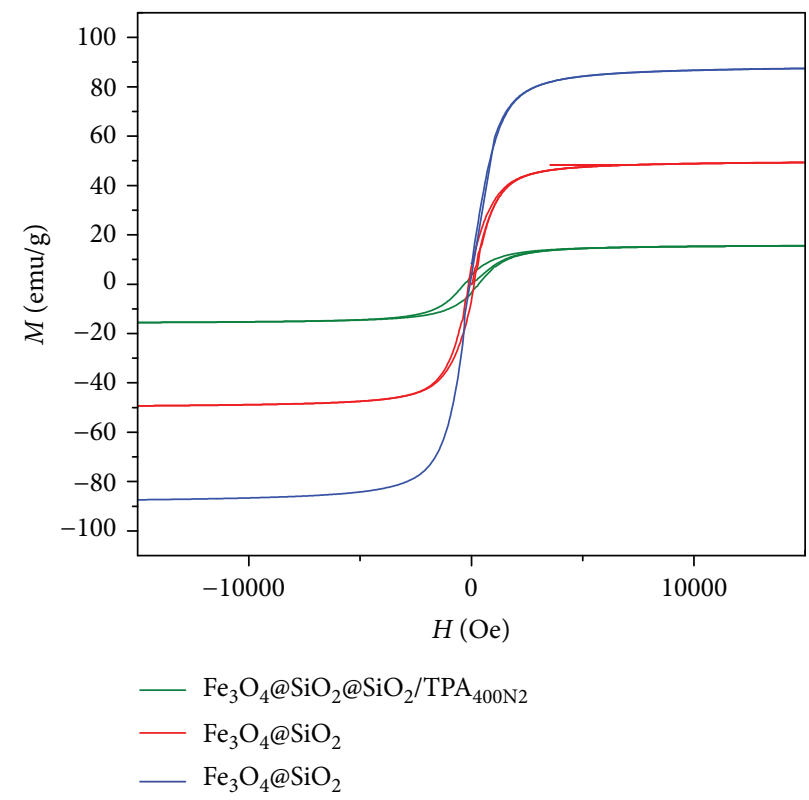

(a)
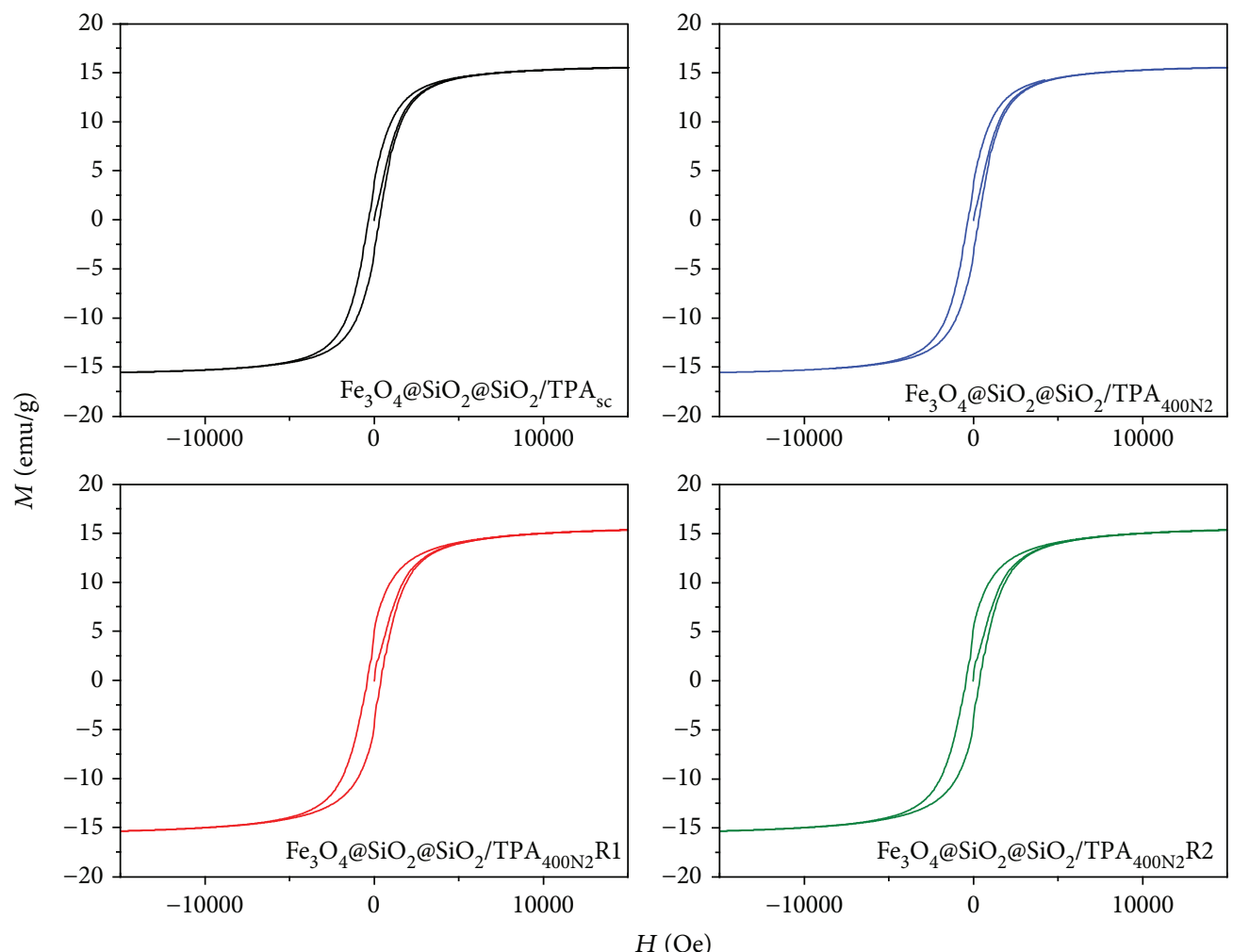

(b)

Figure 5: (a) Magnetization curves for magnetic materials. (b) Magnetization curves for the catalyst after several cycles of reaction.

considerably to $15 \mathrm{emu} / \mathrm{g}$, evidencing that the $\mathrm{SiO}_{2}$ layer is much thicker, with the consequent lower amount of magnetite per unit area. In addition, a slight hysteresis loop can be observed, indicating that the catalyst has a small remanence, probably due to a significant increase in size of the catalyst particles, to a lower crystallinity, or to changes in the surface structure, as evidenced in the XRD analysis. The content of impurities or deficient crystallization of $\mathrm{SiO}_{2} / \mathrm{TPA}$ can affect the magnetic behavior of the powder synthesized, reducing the maximum magnetization and slightly increasing the coercive force $[26,31]$. Even so, its magnetization is sufficient to easily separate the solid from the reaction medium with a conventional magnet. Finally, the magnetic behavior of the uncalcined and calcined materials, after two reaction cycles, 


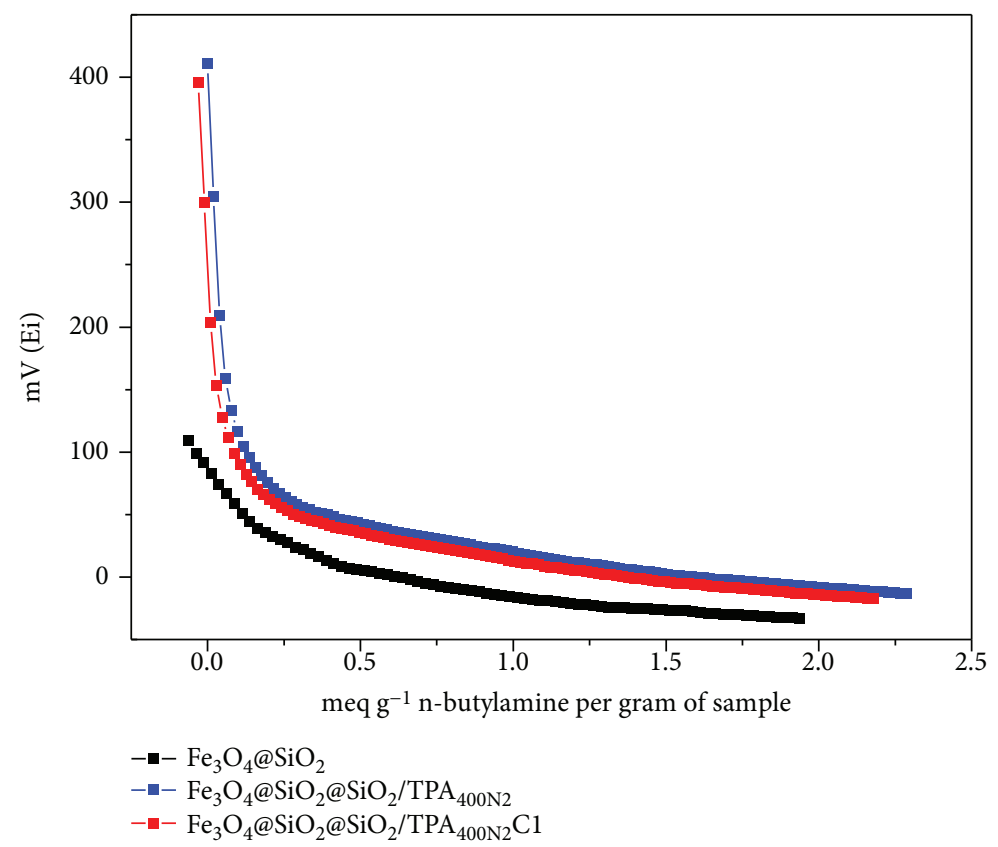

Figure 6: Potentiometric titration curves for $\mathrm{Fe}_{3} \mathrm{O}_{4} @ \mathrm{SiO}_{2}, \mathrm{Fe}_{3} \mathrm{O}_{4} @ \mathrm{SiO}_{2} @ \mathrm{SiO}_{2} / \mathrm{TPA}_{400 \mathrm{~N}}$, and $\mathrm{Fe}_{3} \mathrm{O}_{4} @ \mathrm{SiO}_{2} @ \mathrm{SiO}_{2} / \mathrm{TPA}_{400 \mathrm{~N}} \mathrm{Cl}_{\text {solids. }}$

was analyzed and compared to see whether the calcination temperature and the reaction medium had any effect on their magnetic properties. The resulting curves are shown in Figure 5(b). It can be seen that the $M_{\mathrm{S}}$ value remains at $15 \mathrm{emu} / \mathrm{g}$ in the 4 samples and maintains the same hysteresis cycle, indicating that the $\mathrm{SiO}_{2}$ layers protect the magnetite from abrupt changes of temperature and reaction medium.

The acidity of the solids was determined by potentiometric titration with n-butylamine; the curves obtained for the $\mathrm{Fe}_{2} \mathrm{O}_{4} @ \mathrm{SiO}_{2}$ support, the $\mathrm{Fe}_{3} \mathrm{O}_{4} @ \mathrm{SiO}_{2} @ \mathrm{SiO}_{2} / \mathrm{T}$ $\mathrm{PA}_{400 \mathrm{~N} 2}$ catalyst, and a catalyst sample after the first reaction cycle, $\mathrm{Fe}_{3} \mathrm{O}_{4} @ \mathrm{SiO}_{2} @ \mathrm{SiO}_{2} / \mathrm{TPA}_{400 \mathrm{~N} 2} \mathrm{Cl}$, are shown in Figure 6. The $\mathrm{Fe}_{2} \mathrm{O}_{4} @ \mathrm{SiO}_{2}$ support showed very strong sites, with an Ei value of $110 \mathrm{mV}$. This value increased significantly to $410 \mathrm{mV}$ after the TPA was included in a second $\mathrm{SiO}_{2}$ layer. However, as expected, by including TPA in $\mathrm{Fe}_{2} \mathrm{O}_{4} @ \mathrm{SiO}_{2}$, the strength of the acid sites decreased compared to the value recorded for the bulk TPA, which has an Ei value of $620 \mathrm{mV}$. This is an effect that depends on the degree of interaction of TPA with the support, in this case indicating a strong interaction between the protons of $\mathrm{H}_{3} \mathrm{PW}_{12} \mathrm{O}_{40} \cdot 6 \mathrm{H}_{2} \mathrm{O}$ and the oxygen of the $\mathrm{Si}-\mathrm{OH}$ groups. Furthermore, a good dispersion of TPA on the support is demonstrated by the absence of leaching during the reaction [32]. It can be seen that the potentiometric titration curve of $\mathrm{Fe}_{3} \mathrm{O}_{4} @ \mathrm{SiO}_{2} @ \mathrm{SiO}_{2} / \mathrm{TPA}_{400 \mathrm{~N} 2} \mathrm{Cl}$ gives an Ei value of $395 \mathrm{mV}$, which is slightly smaller compared to the unused catalyst Ei value $(410 \mathrm{mV})$. The form and the potentials of the two curves are very similar, demonstrating that the amount leached during the reaction is very small, which is in agreement with the results obtained in the reuse experiment (4 cycles), exhibiting an excellent activity in esterification reactions.

\subsection{Kinetic Study}

3.2.1. External Mass Transfer Resistance. One way of experimentally determining the external resistance to mass transfer is the stirring test, since, in the case of gas-solid and liquid-solid systems, when the conversion does not depend on the stirring rate, it can be said that the system is free of interfacial limitations [33]. The test consists of carrying out different reactions by keeping the molar ratio of reactants, catalyst weight, and temperature constant and varying the stirring rate for a given time. In the range of stirring rates in which the conversion is kept constant, it can be said that there are no diffusion effects. In this case, the experimental conditions were $313 \mathrm{~K}$, an initial acid/alcohol molar ratio of $1: 2$, catalyst of $100 \mathrm{mg}$, and stirring rates of $100,250,500,750$, and $1000 \mathrm{rpm}$ for $3 \mathrm{~h}$. It was found that in the interval between 100 and $1000 \mathrm{rpm}$, there was no effect of the stirring speed on the conversion of LEA, since in all cases the conversion was $10.0 \% \pm 0.2$. Thus, all the experiments were performed at a stirring rate of $500 \mathrm{rpm}$ to ensure the absence of external resistance.

3.2.2. Internal Mass Transfer Resistance. The Weisz-Prater (WP) criterion $\left(N_{\mathrm{W}-\mathrm{P}}\right)$ [34] was used to evaluate the influence of intraparticle diffusion resistance at each temperature. Such a calculation makes it possible to establish the absence of any pore diffusion limitation or to warn of its presence. The criterion states that an $N_{\mathrm{W}-\mathrm{P}}$ value below 0.3 for a reaction order in the substrate of 2 or less is indicative of the absence of significant diffusion limitations. To use the WP criterion successfully, the effective diffusivity coefficient $\left(D_{\text {eff }}\right)$ of a reagent in a given catalytic system must be determined accurately. In this case, it would involve determining the effective diffusivity of LEA (A) in $\mathrm{BOH}$ (B) $D_{\mathrm{AB}}$ 


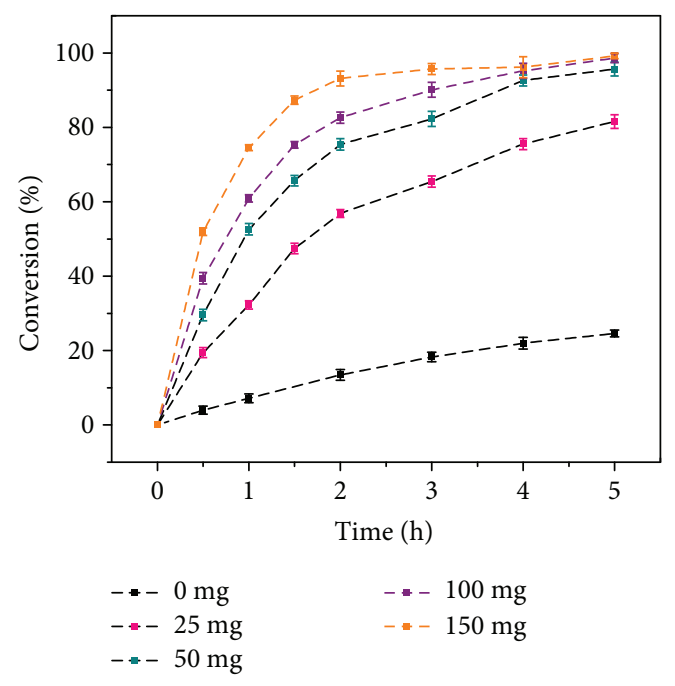

FIgURE 7: Influence of catalyst amount on the conversion of BLE with $\mathrm{Fe}_{3} \mathrm{O}_{4} @ \mathrm{SiO}_{2} @ \mathrm{SiO}_{2} / \mathrm{TPA}_{400 \mathrm{~N} 2}$ as catalyst. Reaction conditions: molar ratio of reactants $1: 2$, temperature $353 \mathrm{~K}$, and $5 \mathrm{~h}$ reaction.

(calculated from the Wilke-Chang criterion, porosity, and tortuosity), reaction rate, particle radius, and concentration of the reactants on the outer surface of the particle. For the latter, it was assumed that when the external mass transfer limitations can be discarded, the concentration of substances on the catalyst surface is taken equal to the mass concentration of the substances $\left(C_{\mathrm{A}}=C_{\mathrm{B}}\right)$. Thus, the mass concentration of $\mathrm{A}$ at the beginning of the reaction is known for all experiments. Since the $N_{\mathrm{W}-\mathrm{P}}$ values determined for each temperature used during the catalytic test in all cases were much lower than 0.3 , it can be established that there is no resistance to intraparticle diffusion, which is important, since, in a kinetic study, it is necessary to generate data that are free of mass and energy transport limitations (the equations and calculations performed are shown in the Supplementary Material; similarly, the determined $N_{\mathrm{W}-\mathrm{P}}$ data are provided in Table S1).

\subsection{Optimization of the Reaction Conditions}

3.3.1. Influence of the Catalyst Amount. The catalyst amount was initially studied in the range from 25 to $150 \mathrm{mg}$ under the same reaction conditions, namely, an acid/alcohol molar ratio equal to $1: 2$ and a temperature of $353 \mathrm{~K}$ for $5 \mathrm{~h}$. The reaction profiles are shown in Figure 7. Since there are no external diffusion limitations, the reaction rate is proportional to the amount of catalyst, because there are a greater number of acid sites. In the absence of catalyst, a conversion of $25 \%$ in $5 \mathrm{~h}$ was only obtained, as the acidity of LEA catalyzed the reaction, which was further favored by an increase in temperature, since at $323 \mathrm{~K}$ it gave a conversion of $15 \%$ in $24 \mathrm{~h}$. However, this is a lower value compared to the conversion obtained in the presence of the catalyst $\mathrm{Fe}_{3} \mathrm{O}_{4} @$ $\mathrm{SiO}_{2} @ \mathrm{SiO}_{2} / \mathrm{TPA}_{400 \mathrm{~N} 2}$, in which case with $25 \mathrm{mg}$ of catalyst, a conversion of $82 \%$ was reached and with amounts of 50,100 , and $150 \mathrm{mg}$ the conversion were $95 \%, 98 \%$, and $100 \%$, respectively. The values were significantly close, so

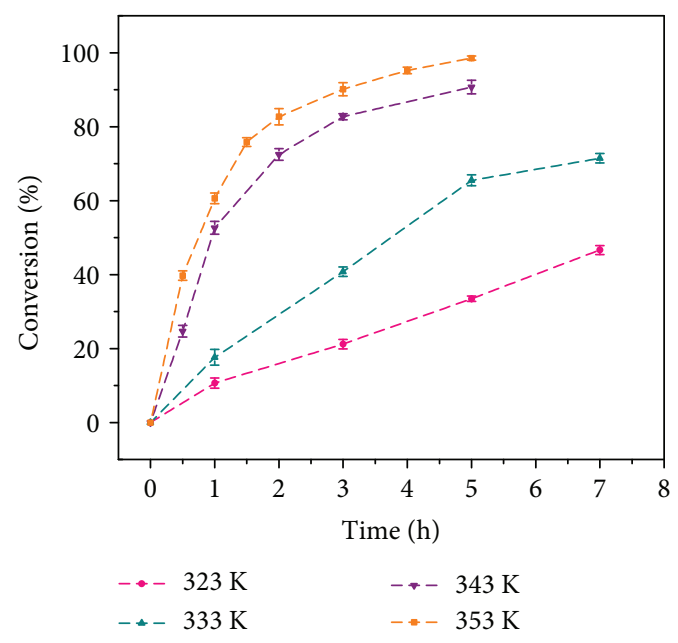

FIGURE 8: Influence of the reaction temperature on the conversion of $\mathrm{BLE}$ with $\mathrm{Fe}_{3} \mathrm{O}_{4} @ \mathrm{SiO}_{2} @ \mathrm{SiO}_{2} / \mathrm{TPA}_{400 \mathrm{~N} 2}$ as catalyst. Reaction conditions: $1: 2$ molar ratio of reactants, $100 \mathrm{mg}$ of catalyst, and $7 \mathrm{~h}$ reaction.

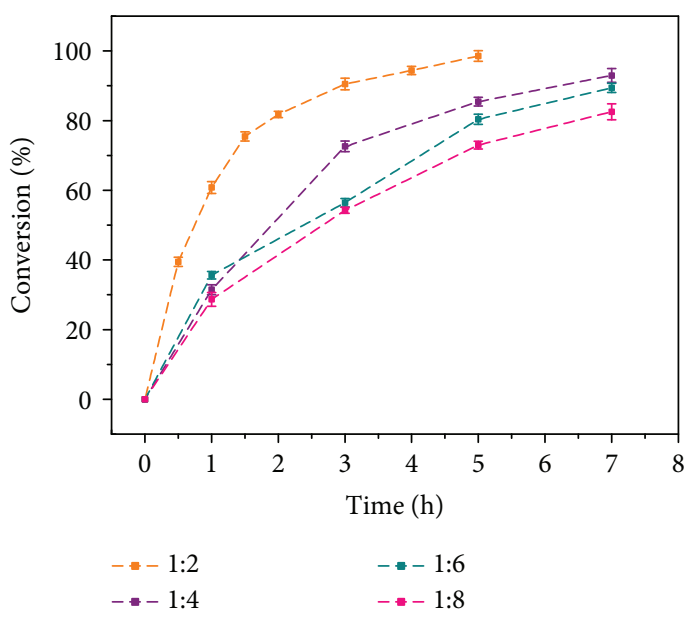

FIgURE 9: Influence of the acid/alcohol molar ratio on the conversion of $\mathrm{BLE}$ with $\mathrm{Fe}_{3} \mathrm{O}_{4} @ \mathrm{SiO}_{2} @ \mathrm{SiO}_{2} / \mathrm{TPA}_{400 \mathrm{~N} 2}$ as catalyst $(100 \mathrm{mg}), 353 \mathrm{~K}$, and $7 \mathrm{~h}$ reaction.

a load of $100 \mathrm{mg}$ per mole of LEA was chosen as the optimum catalyst amount.

3.3.2. Influence of Temperature. The influence of the reaction temperature on the conversion of BLE was studied in a range between 323 and $353 \mathrm{~K}$ (Figure 8). Not only did a significant increase in the conversion of the reaction was observed when the temperature was raised, but the reaction rate also increased, achieving a conversion of $100 \%$ in $5 \mathrm{~h}$ at $353 \mathrm{~K}$ compared to the $42 \%$ conversion in $7 \mathrm{~h}$ that was reached at $323 \mathrm{~K}$. This suggests a kinetically controlled mechanism. An increase in the reaction temperature leads to drastic increases in collisions between reactant species and the catalyst. In consequence, the reaction rate increases, which favors the formation of BLE. In addition, the esterification reaction is an equilibrium reaction that generates water as one of the 


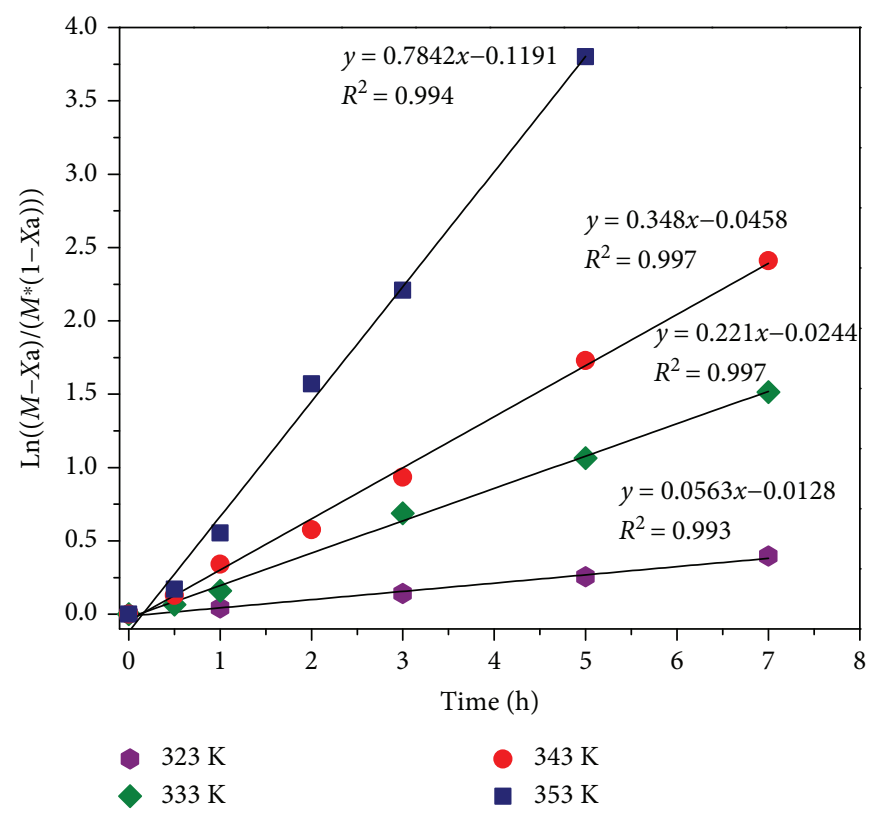

Figure 10: $\ln \left(M-X_{\mathrm{A}}\right) / M\left(1-X_{\mathrm{A}}\right)$ against reaction time at different temperatures for the esterification of LEA with BOH on $\mathrm{Fe}_{3} \mathrm{O}_{4} @ \mathrm{SiO}_{2} @ \mathrm{SiO}_{2} / \mathrm{TPA}_{400 \mathrm{~N} 2}$ under optimized reaction conditions to obtain the reaction rate constants $\left(k_{\mathrm{s}}\right)$ at each temperature.

products. As the temperature increases, the water is removed from the system, displacing the equilibrium towards ester formation. It can be seen in Figure 8 that at $323 \mathrm{~K}$, the reaction is slow and the reaction rate significantly increases at 343 and $353 \mathrm{~K}$.

3.3.3. Influence of the Acid/Alcohol Molar Ratio. Another way of shifting the equilibrium towards the formation of BLE is by using an excess of alcohol, but in this case (Figure 9), an opposite effect was obtained, which agrees with the one published by Patil et al. [35], who found that a low molar ratio of alcohol to LEA, in the range of 2 to 5, favors the reaction. The said behavior is explained because an overly diluted system could involve limitations of the mass transfer of reactant to the catalyst and stimulate the intermolecular dehydration of the alcohol as a by-product, which occurs at low temperatures and a higher reactant molar ratio. In our case, the best molar ratio was $1: 2$, which favors the reaction rate and selectivity and allows it to be run in solvent-free conditions, with the additional advantage of improving the process of eco-compatibility.

3.4. Kinetic Model. With the experimental data presented previously, a kinetic model was constructed according to the reaction under study. The reaction can be described by either a pseudohomogeneous $(\mathrm{pH})$, Langmuir-Hinshelwood (LH), or Eley-Rideal (ER) model. An overall rate of expression assuming that the slowest step is the surface reaction and not the adsorption and desorption steps is expressed as

$$
\frac{-\mathrm{d} C_{\mathrm{A}}}{\mathrm{d} t}=\frac{k_{\mathrm{s}} C_{\mathrm{A}} C_{\mathrm{B}} C_{t}^{2}}{\left(1+\sum k_{i} C_{i}\right)^{n}},
$$

where $n=0$ for the $\mathrm{pH}$ model, $n=1$ for the ER model, and $n=2$ for the LH model. This equation has been described by various authors in the esterification of organic acids [36-39]. Assuming that for the esterification of LEA, there is a weak sorption of reaction components on the catalyst surface (equilibrium constants of adsorption are low) so that the term $\sum k_{i} C_{i}$ in the denominator is almost negligible [40]; the expression of the $\mathrm{pH}$ model is reduced to

$$
\frac{-\mathrm{d} C_{\mathrm{A}}}{\mathrm{d} t}=k_{\mathrm{s}} C_{\mathrm{A}} C_{\mathrm{B}}
$$

where $k_{\mathrm{s}}=K_{\tau} \omega y \omega=$ catalyst loading.

This expression is commonly used in the esterification of LEA $[12,41]$. In this sense, equation (3) can be rewritten in terms of fractional conversion as follows:

$$
\frac{-\mathrm{d}\left(X_{\mathrm{A}}\right)}{\mathrm{d} t}=k_{\mathrm{s}} C_{\mathrm{A}}\left(1-X_{\mathrm{A}}\right)\left(M-X_{\mathrm{A}}\right)
$$

where $M=\left(C_{\mathrm{Bo}} / C_{\mathrm{Ao}}\right)$, and $C_{\mathrm{A}}$ and $C_{\mathrm{A} 0}$ are the concentrations of LEA at any reaction time and initial time, respectively. Solving the integral form of (4), we have

$$
\ln \left(\frac{M-X_{\mathrm{A}}}{M\left(1-X_{\mathrm{A}}\right)}\right)=K_{\tau} \omega C_{\mathrm{Ao}}(M-1) t
$$

Plots of $\ln \left(M-X_{\mathrm{A}}\right) / M\left(1-X_{\mathrm{A}}\right)$ against reaction time at different temperatures are shown in Figure 10. In all cases, the curves are linear indicating that the esterification of LEA with $\mathrm{BOH}$ is of the second order.

To improve the adjustment of the kinetic model, the adsorption steps of the reactants or the products should be considered. It is well established that the esterification reactions can be ascribed to either a Langmuir-Hinshelwood or Eley-Rideal pathway [42]. To avoid the contribution of 


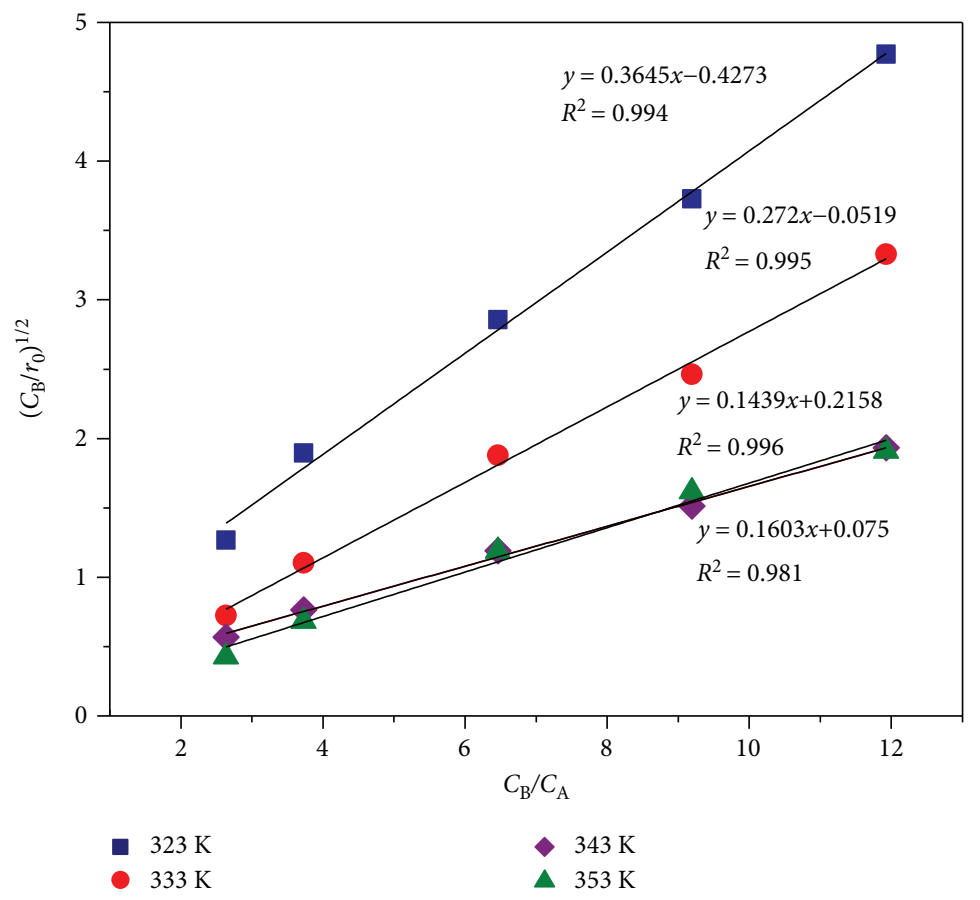

Figure 11: Plot of $\left(C_{\mathrm{B} 0} / r_{\exp }\right)^{1 / 2}$ against $C_{\mathrm{B} 0} /\left(C_{\mathrm{A} 0}\right)^{0.5}$ at different temperatures.

products and simplify the overall reaction scheme, the initial reaction rates were only considered. The initial reaction rate was calculated using a differential method at time zero and the following equation:

$$
-r_{\exp }=\frac{-\mathrm{d} C_{\mathrm{A}}}{\mathrm{d} t} \frac{C_{\mathrm{Ao}}}{w}
$$

The plots of the initial reaction rate as a function of $C_{\mathrm{A} 0}$ or $C_{\mathrm{B} 0}$ (not shown) describe a linear dependence with increasing LEA, but decreases linearly with increasing $\mathrm{BOH}$. This behavior is explained due to saturation of the catalyst surface with the alcohol, thereby stopping the reaction by blocking the adsorption of LEA. The reaction occurs between the two reagents, levulinic acid (A) and n-butanol (B), in only one active acid site (S), but as was previously mentioned, the alcohol has an inhibiting effect. Considering an $\mathrm{LH}$ expression and assuming that the adsorption of $\mathrm{BOH}$ is stronger than the adsorption of LEA, then $K_{\mathrm{A}} C_{\mathrm{A}}<<0$, equation (2) could be simplified to

$$
r_{\exp }=\frac{k_{\mathrm{s}} C_{\mathrm{A}_{0}} C_{\mathrm{B}_{0}}}{\left(1+K_{\mathrm{B}} C_{\mathrm{B}_{0}}\right)^{2}}
$$

The linearization of equation (7) allows a plot of $\left(C_{\mathrm{B} 0} / r_{\text {exp }}\right)^{1 / 2}$ against $C_{\mathrm{B} 0} /\left(C_{\mathrm{A} 0}\right)^{0.5}$ (Figure 11) yielding a slope $=K_{\mathrm{B}} / / \sqrt{ } k_{\mathrm{s}}$ and an intercept $=1 / \sqrt{k_{\mathrm{s}} C_{\mathrm{A}_{0}}}$. The fit was found to be good at different temperatures, and the reaction rate and adsorption constants thus obtained are summarized in Table 2.
TABLE 2: Reaction rate and adsorption constants obtained at different temperatures.

\begin{tabular}{lcc}
\hline Temperature $(\mathrm{K})$ & $k_{\mathrm{s}}\left(\mathrm{mol} \mathrm{min} \mathrm{g}^{-1}\right)$ & $K_{\mathrm{B}}\left(\mathrm{L} \mathrm{mol}^{-1}\right)$ \\
\hline 323 & $1.6 \pm 0.1$ & $0.220 \pm 0.003$ \\
333 & $4.0 \pm 0.1$ & $0.028 \pm 0.004$ \\
343 & $7.7 \pm 0.1$ & $0.018 \pm 0.002$ \\
353 & $18.0 \pm 0.1$ & $0.009 \pm 0.002$ \\
\hline
\end{tabular}

An apparent activation energy of $17 \mathrm{kcal} / \mathrm{mol}$ was determined; besides, the constants of adsorption decrease with the temperatures, which could indicate that the enthalpies and entropies of adsorption are negative, according to their thermodynamic consistency. Considering the saturation of the catalyst surface with the alcohol and a minor adsorption of LEA on one active site and based on this LH model, we propose a plausible reaction mechanism for the esterification of LEA with $\mathrm{BOH}$, which is outlined in Figure 12. The mechanism involves adsorption of $\mathrm{BOH}$ on a Brønsted acid site (B), and subsequently, LEA is activated and attacked by $\mathrm{BOH}$ through an ethoxide mechanism. The stronger adsorption of alcohol in this figure is represented as two molecules of alcohol by the active site, which inhibits the adsorption of LEA and consequently decreases the reaction rate.

\section{Conclusion}

It was possible to include the TPA in materials composed of magnetite encapsulated in silicon oxide $\left(\mathrm{Fe}_{3} \mathrm{O}_{4} @ \mathrm{SiO}_{2}\right)$. The synthesis was monitored and standardized by analyzing the size and morphology of the NPMs by SEM images, 


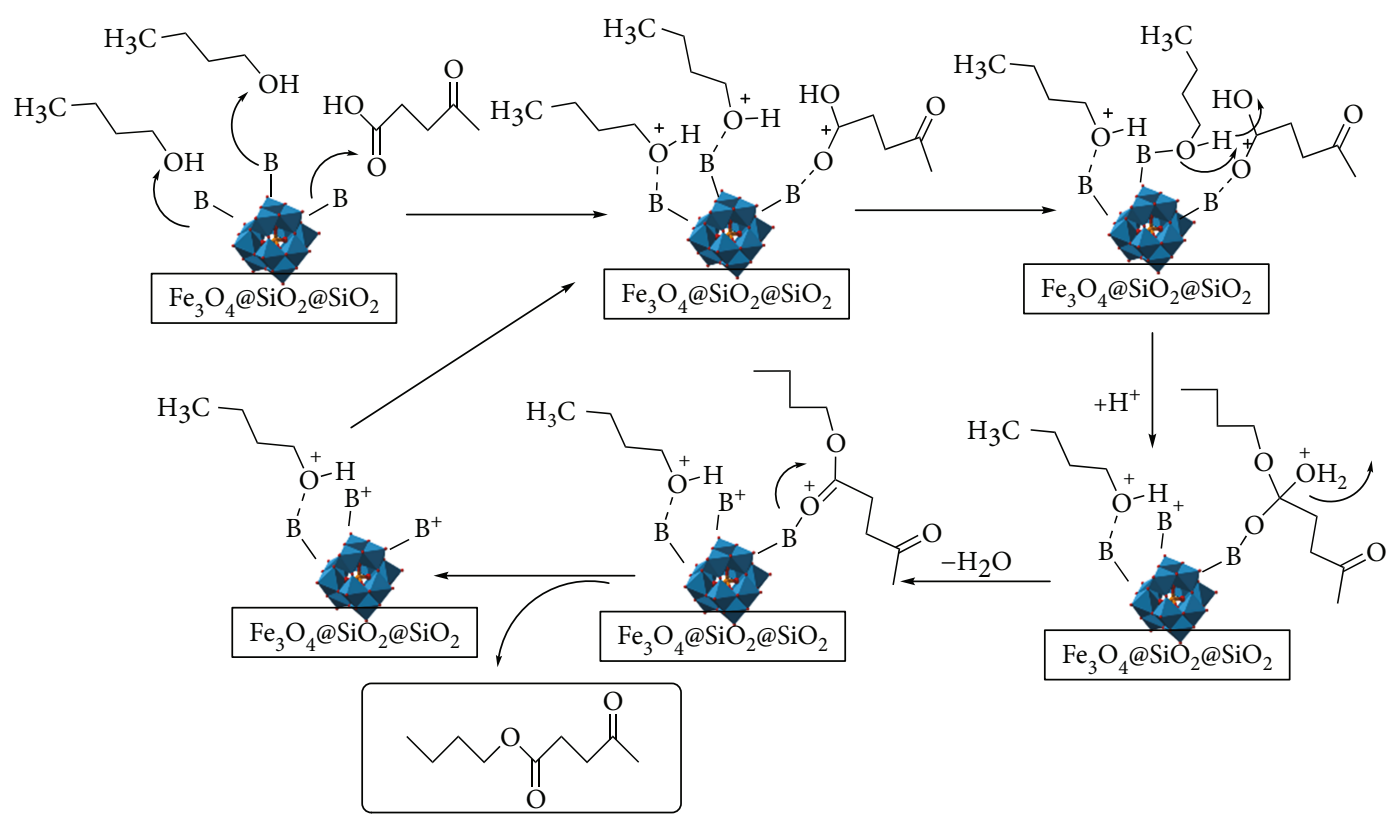

FIGURE 12: Proposed reaction mechanism for the esterification of LEA with BOH for the synthesis of BLE.

determining that they are uniform spheres and they are not affected by factors such as the acidic medium or temperature if they are calcined in an inert atmosphere. The catalyst named $\mathrm{Fe}_{3} \mathrm{O}_{4} @ \mathrm{SiO}_{2} @ \mathrm{SiO}_{2} / \mathrm{TPA}_{400 \mathrm{~N} 2}$ was shown to be active in the synthesis of BLE from LEA and $\mathrm{BOH}$, a product of interest in biomass valorization, with a conversion of $95 \%$, a selectivity of $100 \%$ at $353 \mathrm{~K}$, and up to 4 consecutive reaction cycles without appreciable loss of activity due to poisoning or leaching of the active phase. The influence of various reaction parameters on LEA conversion was studied, determining that the reaction is of second order and was validated successfully by the proposed kinetic model. An activation energy of $17 \mathrm{kcal} / \mathrm{mol}$ was determined. A plausible reaction mechanism based on the ethoxide route is outlined.

\section{Data Availability}

The datasets used to support the finding of this study are available from the corresponding author upon request.

\section{Conflicts of Interest}

The authors declare that there is no conflict of interest regarding the publication of this paper.

\section{Acknowledgments}

This work was financed by the projects of CONICET (PIP 003), ANPCyT, Universidad Nacional de La Plata, and COLCIENCIAS 110965843004, contract: Colciencias-UPTC 047-2015.

\section{Supplementary Materials}

The supplementary material file contains the graphical abstract, the estimated values of the effective diffusion coefficient of levulinic acid (LEA) in n-butanol, additional experimental details (acidity measurements, FT-IR TPA analysis, and reaction product quantification), and related bibliography. (Supplementary Materials)

\section{References}

[1] C. O. Tuck, E. Perez, I. T. Horvath, R. A. Sheldon, and M. Poliakoff, "Valorization of biomass: deriving more value from waste," Science, vol. 337, no. 6095, pp. 695-699, 2012.

[2] I. Spiridon, R. N. Darie-Nita, G. E. Hitruc, J. Ludwiczak, I. A. Cianga Spiridon, and M. Niculaua, "New opportunities to valorize biomass wastes into green materials," Journal of Cleaner Production, vol. 133, pp. 235-242, 2016.

[3] M. FitzPatrick, P. Champagne, M. F. Cunningham, and R. A. Whitney, "A biorefinery processing perspective: treatment of lignocellulosic materials for the production of value-added products," Bioresource Technology, vol. 101, no. 23, pp. 8915-8922, 2010.

[4] B. Kamm, P. Gruber, and M. Kamm, "Biorefineries-industrial processes and products," in Ullmann's Encyclopedia of Industrial Chemistry 5, pp. 659-688, John Wiley \& Sons, 2007.

[5] D. J. Hayes, "An examination of biorefining processes, catalysts and challenges," Catalysis Today, vol. 145, no. 1-2, pp. 138-151, 2009.

[6] T. Werpy and G. Petersen, Top Value Added Chemicals from Biomass Volume I-Results of Screening for Potential Candidates from Sugars and Synthesis Gas, National Renewable Energy Laboratory, 2004.

[7] J. J. Bozell and G. R. Petersen, “Technology development for the production of biobased products from biorefinery 
carbohydrates-the US Department of Energy's “Top 10" revisited," Green Chemistry, vol. 12, no. 4, p. 539, 2010.

[8] (2002) Online Edition, "Specifications for flavourings," Food Agric. Organ. United Nationshttp://www.fao.org/food/ food-safety-quality/scientific-advice/jecfa/jecfa-flav/details/en/ c/1111/.

[9] A. Démolis, N. Essayem, and F. Rataboul, "Synthesis and applications of alkyl levulinates," ACS Sustainable Chemistry \& Engineering, vol. 2, no. 6, pp. 1338-1352, 2014.

[10] K. Yan, C. Jarvis, J. Gu, and Y. Yan, "Production and catalytic transformation of levulinic acid: a platform for speciality chemicals and fuels," Renewable and Sustainable Energy Reviews, vol. 51, pp. 986-997, 2015.

[11] H. J. Bart, J. Reidetschläger, K. Schatka, and A. Lehmann, "Kinetics of esterification of levulinic acid with n-butanol by homogeneous catalysis," Industrial and Engineering Chemistry Research, vol. 33, no. 1, pp. 21-25, 1994.

[12] K. Y. Nandiwale and V. V. Bokade, "Esterification of renewable levulinic acid ton-butyl levulinate over modified H-ZSM-5," Chemical Engineering and Technology, vol. 38, no. 2, pp. 246-252, 2015.

[13] C. W. Lim and I. S. Lee, "Magnetically recyclable nanocatalyst systems for the organic reactions," Nano Today, vol. 5, no. 5, pp. 412-434, 2010.

[14] M. Faraji, Y. Yamini, and M. Rezaee, "Magnetic nanoparticles: synthesis, stabilization, functionalization, characterization, and applications," Journal of the Iranian Chemical Society, vol. 7, no. 1, pp. 1-37, 2010.

[15] A. Bandhu, S. Mukherjee, S. Acharya et al., "Dynamic magnetic behaviour and Mössbauer effect measurements of magnetite nanoparticles prepared by a new technique in the co-precipitation method," Solid State Communications, vol. 149, no. 41-42, pp. 1790-1794, 2009.

[16] J. H. Jang and H. B. Lim, "Characterization and analytical application of surface modified magnetic nanoparticles," Microchemical Journal, vol. 94, no. 2, pp. 148-158, 2010.

[17] S. C. N. Tang and I. M. C. Lo, "Magnetic nanoparticles: essential factors for sustainable environmental applications," Water Research, vol. 47, no. 8, pp. 2613-2632, 2013.

[18] G. H. Du, Z. L. Liu, X. Xia, Q. Chu, and S. M. Zhang, "Characterization and application of $\mathrm{Fe}_{3} \mathrm{O}_{4} / \mathrm{SiO}_{2}$ nanocomposites," Journal of Sol-Gel Science and Technology, vol. 39, no. 3, pp. 285-291, 2006.

[19] E. Rafiee and S. Eavani, "Controlled immobilization of Keggintype heteropoly acids on the surface of silica encapsulated $\gamma$ $\mathrm{Fe}_{2} \mathrm{O}_{3}$ nanoparticles and investigation of catalytic activity in the oxidative esterification of arylaldehydes with methanol," Journal of Molecular Catalysis A: Chemical, vol. 373, pp. 30-37, 2013.

[20] E. Rafiee and S. Eavani, " $\mathrm{H}_{3} \mathrm{PW}_{12} \mathrm{O}_{40}$ supported on silicaencapsulated $\gamma-\mathrm{Fe}_{2} \mathrm{O}_{3}$ nanoparticles: a novel magneticallyrecoverable catalyst for three-component Mannich-type reactions in water," Green Chemistry, vol. 13, no. 8, p. 2116, 2011.

[21] H. Eshghi, A. Khojastehnezhad, F. Moeinpour, M. Bakavoli, S. M. Seyedi, and M. Abbasi, "Synthesis, characterization and first application of keggin-type heteropoly acids supported on silica coated $\mathrm{NiFe}_{2} \mathrm{O}_{4}$ as novel magnetically catalysts for the synthesis of tetrahydropyridines," RSC Advances, vol. 4, no. 75, article 39782, 2014.

[22] J. Yuan, P. Yue, and L. Wang, "A study on the magnetically supported heteropolyacid nanophase catalysts," Powder Technology, vol. 202, no. 1-3, pp. 190-193, 2010.
[23] A. M. Escobar Caicedo, J. A. Rengifo-Herrera, P. Florian, M. N. Blanco, G. P. Romanelli, and L. R. Pizzio, "Valorization of biomass derivatives: Keggin heteropolyacids supported on titania as catalysts in the suitable synthesis of 2-phenoxyethyl-2-furoate," Journal of Molecular Catalysis A: Chemical, vol. 425, pp. 266-274, 2016.

[24] A. Escobar, Á. Sathicq, L. Pizzio, M. Blanco, and G. Romanelli, "Biomass valorization derivatives: clean esterification of 2furoic acid using tungstophosphoric acid/zirconia composites as recyclable catalyst," Process Safety and Environment Protection, vol. 98, pp. 176-186, 2015.

[25] W. Wu, Z. Wu, T. Yu, C. Jiang, and W. S. Kim, "Recent progress on magnetic iron oxide nanoparticles: synthesis, surface functional strategies and biomedical applications," Science and Technology of Advanced Materials, vol. 16, no. 2, article 023501, 2015.

[26] A. P. A. Faiyas, E. M. Vinod, J. Joseph, R. Ganesan, and R. K. Pandey, "Dependence of $\mathrm{pH}$ and surfactant effect in the synthesis of magnetite $\left(\mathrm{Fe}_{3} \mathrm{O}_{4}\right)$ nanoparticles and its properties," Journal of Magnetism and Magnetic Materials, vol. 322, no. 4, pp. 400-404, 2010.

[27] M. E. Khosroshahi and L. Ghazanfari, "Preparation and characterization of silica-coated iron-oxide bionanoparticles under $\mathrm{N}_{2}$ gas," Physica E: Low-dimensional Systems and Nanostructures, vol. 42, no. 6, pp. 1824-1829, 2010.

[28] Z. Zhang, F. Zhang, Q. Zhu, W. Zhao, B. Ma, and Y. Ding, "Magnetically separable polyoxometalate catalyst for the oxidation of dibenzothiophene with $\mathrm{H}_{2} \mathrm{O}_{2}$," Journal of Colloid and Interface Science, vol. 360, no. 1, pp. 189-194, 2011.

[29] C. M. Sorensen, "Frontmatter and index," in Nanoscale Materials in Chemistry, K. J. Klabunde, Ed., pp. i-xi, John Wiley \& Sons, Inc., New York, NY, USA, 2001.

[30] M. A. Ghasemzadeh, M. H. Abdollahi-Basir, and M. Babaei, " $\mathrm{Fe}_{3} \mathrm{O}_{4} @ \mathrm{SiO}_{2}-\mathrm{NH}_{2}$ core-shell nanocomposite as an efficient and green catalyst for the multi-component synthesis of highly substituted chromeno[2,3-b]pyridines in aqueous ethanol media," Green Chemistry Letters and Reviews, vol. 8, no. 3-4, pp. 40-49, 2015.

[31] A. A. Jahagirdar, N. Dhananjaya, D. L. Monika et al., "Structural, EPR, optical and magnetic properties of $\alpha-\mathrm{Fe}_{2} \mathrm{O}_{3}$ nanoparticles," Spectrochimica Acta Part A: Molecular and Biomolecular Spectroscopy, vol. 104, pp. 512-518, 2013.

[32] E. Rafiee and M. Khodayari, "Synthesis and characterization of a green composite of $\mathrm{H}_{3} \mathrm{PW}_{12} \mathrm{O}_{40}$ and starch-coated magnetite nano particles as a magnetically-recoverable nano catalyst in Friedel-crafts alkylation," Journal of Molecular Catalysis A: Chemical, vol. 398, pp. 336-343, 2015.

[33] C. Perego, "Experimental methods in catalytic kinetics," Catalysis Today, vol. 52, no. 2-3, pp. 133-145, 1999.

[34] M. A. Vannice, Kinetics of Catalytic Reactions, Springer, USA, 2005.

[35] C. R. Patil, P. S. Niphadkar, V. V. Bokade, and P. N. Joshi, "Esterification of levulinic acid to ethyl levulinate over bimodal micro-mesoporous H/BEA zeolite derivatives," Catalysis Communications, vol. 43, pp. 188-191, 2014.

[36] S. Y. Chin, A. L. Ahmad, A. R. Mohamed, and S. Bhatia, "Characterization and activity of zinc acetate complex supported over functionalized silica as a catalyst for the production of isopropyl palmitate," Applied Catalysis A: General, vol. 297, no. 1, pp. 8-17, 2006. 
[37] K. Srilatha, N. Lingaiah, P. S. Sai Prasad, B. L. A. Prabhavathi Devi, and R. B. N. Prasad, "Kinetics of the esterification of palmitic acid with methanol catalyzed by 12tungstophosphoric acid supported on $\mathrm{ZrO}_{2}$," Reaction Kinetics, Mechanisms and Catalysis, vol. 104, no. 1, pp. 211-226, 2011.

[38] S. R. Kirumakki, N. Nagaraju, and S. Narayanan, "A comparative esterification of benzyl alcohol with acetic acid over zeolites H $\beta$, HY and HZSM5," Applied Catalysis A: General, vol. 273, no. 1-2, pp. 1-9, 2004.

[39] S. R. Kirumakki, N. Nagaraju, and K. V. R. Chary, "Esterification of alcohols with acetic acid over zeolites $\mathrm{H} \beta$, HY and HZSM5," Applied Catalysis A: General, vol. 299, pp. 185-192, 2006.

[40] P. Zamostny and Z. Belohlav, "Identification of kinetic models of heterogeneously catalyzed reactions," Applied Catalysis A: General, vol. 225, no. 1-2, pp. 291-299, 2002.

[41] K. Y. Nandiwale, S. K. Sonar, P. S. Niphadkar et al., "Catalytic upgrading of renewable levulinic acid to ethyl levulinate biodiesel using dodecatungstophosphoric acid supported on desilicated H-ZSM-5 as catalyst," Applied Catalysis A: General, vol. 460-461, pp. 90-98, 2013.

[42] P. Delgado, M. T. Sanz, and S. Beltrán, "Kinetic study for esterification of lactic acid with ethanol and hydrolysis of ethyl lactate using an ion-exchange resin catalyst," Chemical Engineering Journal, vol. 126, no. 2-3, pp. 111-118, 2007. 


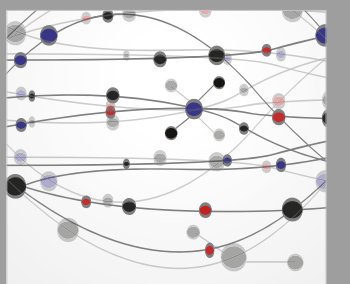

The Scientific World Journal
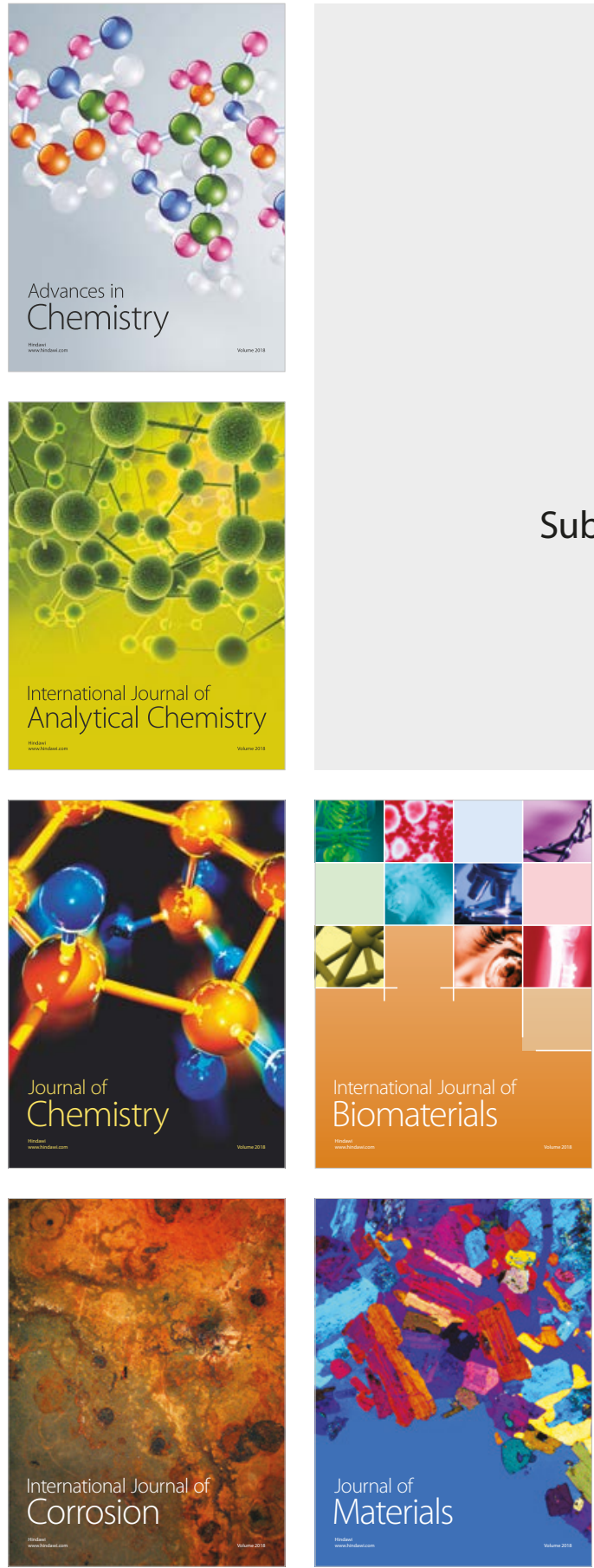

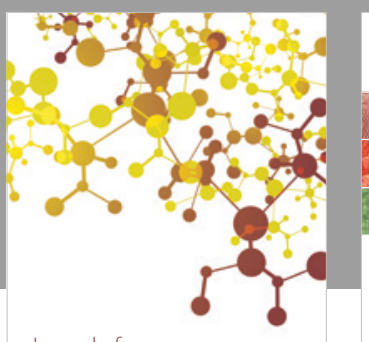

Journal of

Applied Chemistry
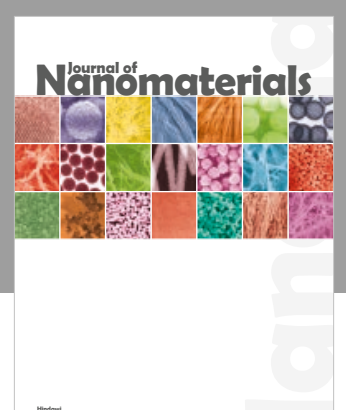

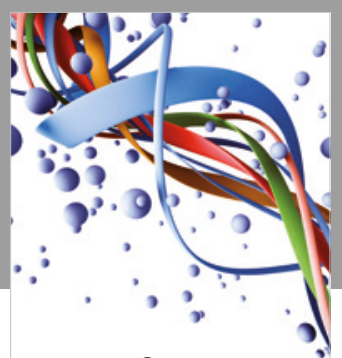

Scientifica

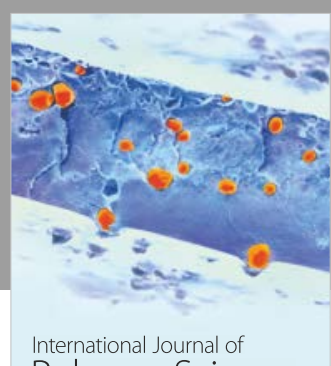

Polymer Science

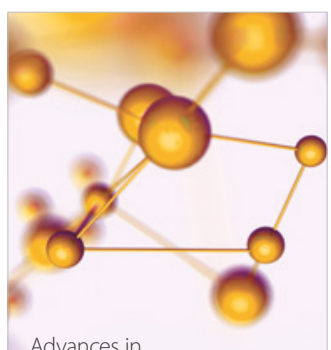

Physical Chemistry
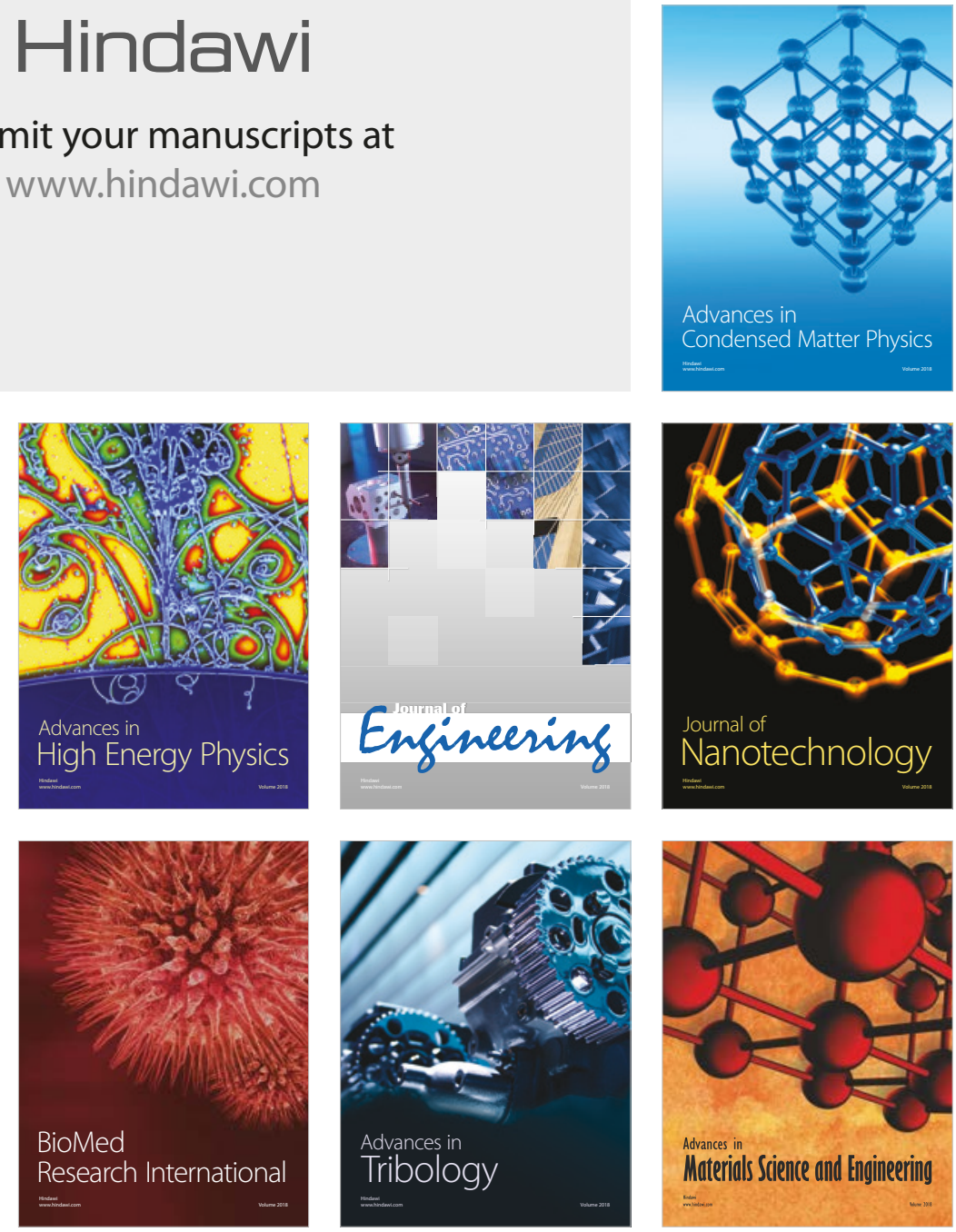